\title{
Activity-Dependent Rapid Local RhoA Synthesis Is Required for Hippocampal Synaptic Plasticity
}

\author{
Victor Briz, ${ }^{1}$ Guoqi Zhu, ${ }^{1}$ Yubin Wang, ${ }^{1}$ Yan Liu ${ }^{1,2}$ Mariam Avetisyan, ${ }^{1}$ Xiaoning Bi, ${ }^{2}$ and Michel Baudry ${ }^{1}$ \\ ${ }^{1}$ Graduate College of Biomedical Sciences and ${ }^{2}$ College of Osteopathic Medicine of the Pacific Western University of Health Sciences, Pomona, California \\ 91766
}

Dendritic protein synthesis and actin cytoskeleton reorganization are important events required for the consolidation of hippocampal LTP and memory. However, the temporal and spatial relationships between these two processes remain unclear. Here, we report that treatment of adult rat hippocampal slices with BDNF or with tetraethylammonium (TEA), which induces a chemical form of LTP, produces a rapid and transient increase in RhoA protein levels. Changes in RhoA were restricted to dendritic spines of CA3 and CA1 and require de novo protein synthesis regulated by mammalian target of rapamycin (mTOR). BDNF-mediated stimulation of RhoA activity, cofilin phosphorylation, and actin polymerization were completely suppressed by protein synthesis inhibitors. Furthermore, intrahippocampal injections of RhoA antisense oligodeoxynucleotides inhibited theta burst stimulation (TBS)-induced RhoA upregulation in dendritic spines and prevented LTP consolidation. Addition of calpain inhibitors after BDNF or TEA treatment maintained RhoA levels elevated and prolonged the effects of BDNF and TEA on actin polymerization. Finally, the use of isoform-selective calpain inhibitors revealed that calpain-2 was involved in RhoA synthesis, whereas calpain-1 mediated RhoA degradation. Overall, this mechanism provides a novel link between dendritic protein synthesis and reorganization of the actin cytoskeleton in hippocampal dendritic spines during LTP consolidation.

Key words: actin cytoskeleton; BDNF; calpain; dendritic protein synthesis; LTP

\section{Introduction}

Structural and functional changes that take place in dendritic spines during LTP of synaptic transmission are widely thought to participate in memory formation. Reorganization of the actin cytoskeleton is a necessary step for LTP consolidation in hippocampus (Lynch and Baudry, 1984; Lynch et al., 2007; Rex et al., 2007). Similarly, dendritic protein synthesis has been shown to be required for certain forms of synaptic plasticity (Sutton and Schuman, 2006; Abraham and Williams, 2008; Panja and Bramham, 2014). BDNF plays a major role in activity-dependent synaptic modifications, through stimulation of both actin polymerization and mammalian target of rapamycin (mTOR)-mediated protein translation (Rex et al., 2007; Jourdi et al., 2009). However, the temporal and spatial relationships between these two important events are not yet fully understood.

Actin cytoskeleton represents a highly regulated complex, which undergoes dynamic equilibrium between globular actin and filamentous actin (F-actin). Among the numerous regula-

\footnotetext{
Received June 5, 2014; revised Nov. 5, 2014; accepted Dec. 18, 2014.

Author contributions: V.B. and M.B. designed research; V.B., G.Z., Y.W., Y.L., and M.A. performed research; V.B. and G.Z. analyzed data; V.B., X.B., and M.B. wrote the paper.

This work was supported by National Institute of Neurological Disorders and Stroke Grant P01NS045260-01 (principal investigator Dr. C.M. Gall) and National Institute of Neurological Disorders and Stroke Grant R01NS057128 to M.B.

The authors declare no competing financial interests.

Correspondence should be addressed to Dr. Michel Baudry, Western University of Health Sciences, 309 East 2nd Street, Pomona, CA 91766-1854. E-mail: mbaudry@westernu.edu.

DOI:10.1523/JNEUROSCI.2302-14.2015

Copyright $\odot 2015$ the authors $\quad 0270-6474 / 15 / 352269-14 \$ 15.00 / 0$
}

tory elements participating in this equilibrium, the Rho family of proteins plays a central role, as they link extracellular signals to a variety of intracellular effectors. These small GTPases (i.e., RhoA, Cdc42, and Rac1) are highly expressed in brain (Olenik et al., 1997) and differentially regulate spine morphology during neuronal development (Nakayama et al., 2000; Penzes and Rafalovich, 2012). Stimulation of the RhoA/RhoA kinase (ROCK) pathway has been proposed to drive actin polymerization and spine growth during LTP, whereas Rac/Cdc42/p21-activated kinase (PAK) signaling seems to be important for F-actin stabilization and maintenance of structural plasticity (Rex et al., 2009; Murakoshi et al., 2011). Both signaling cascades stimulate LIM domain kinase (LIMK)-mediated cofilin phosphorylation to regulate actin filament dynamics (Edwards et al., 1999; Maekawa et al., 1999; Dan et al., 2001). Although BDNF modulates RhoA and Rac signaling in developing neurons (Yuan et al., 2003; Chen et al., 2006; Lin et al., 2011), as well as in non-neuronal cells (Yamauchi et al., 2004; Guo et al., 2012), which pathway(s) mediates the facilitatory effects of BDNF on actin polymerization is not known.

Because protein synthesis was found to be required for LTP consolidation, only a small number of proteins, including calcium/ calmodulin-dependent protein kinase II (CaMKII), protein kinase $\mathrm{M}-\zeta$, and activity-regulated cytoskeleton-associated protein (Arc) (Håvik et al., 2003; Hernandez et al., 2003; Messaoudi et al., 2007), have been shown to be rapidly upregulated following LTP induction. Local RhoA synthesis has previously been shown to contribute to growth cone collapse in DRGs and in hippocampal 
neurons (Wu et al., 2005; Qin et al., 2010). BDNF has also been reported to rapidly stimulate RhoA translation in synaptoneurosomes (Troca-Marín et al., 2010). However, whether RhoA is synthesized in mature neurons in response to synaptic activity is not known; and more importantly, nor is the role, if any, of newly synthesized RhoA in actin cytoskeletal dynamics and hippocampal synaptic plasticity. Here, we report that RhoA is rapidly, locally and transiently upregulated in response to BDNF or chemically induced LTP; moreover, dendritic RhoA synthesis is required for activity-induced synaptic plasticity in area CA1 of hippocampus.

\section{Materials and Methods}

Animals were treated in accordance with the principles and procedures of the National Institutes of Health Guide for the Care and Use of Laboratory Animals; all protocols were approved by the Institutional Animal Care and Use Committee of Western University of Health Sciences.

Acute hippocampal slice preparation and treatments. Hippocampi were acutely prepared from 2- to 3-month-old male Sprague Dawley rats, as previously described (Wang et al., 2014). After $1 \mathrm{~h}$ recovery, hippocampal slices were incubated in oxygenated artificial CSF (aCSF) medium, containing the following (in mM): $\mathrm{NaCl} 124, \mathrm{KCl} 2.5, \mathrm{CaCl}_{2} 2.5, \mathrm{MgSO}_{4}$ $1.5, \mathrm{NaH}_{2} \mathrm{PO}_{4} 1.25, \mathrm{NaHCO}_{3} 24$, D- glucose 10 , and various drugs including $100 \mathrm{ng} / \mathrm{ml}$ BDNF (Millipore) at $37^{\circ} \mathrm{C}$ for the indicated time periods. Samples from different experimental groups were collected at the same time, and control samples are thus always matched for the appropriate time. In some experiments, slices were pretreated for $30 \mathrm{~min}$ with different inhibitors or antagonists, including U0126 (Tocris Bioscience), cycloheximide (Tocris Bioscience), H1152 (Cayman chemicals), PF3758309 (ChemieTek), and rapamycin (Cell Signaling Technology), calpain inhibitor III (Calbiochem), PD151746 (C1I, Millipore) and Z-Leu-Abu-CONH- $\mathrm{CH}_{2}-\mathrm{C}_{6} \mathrm{H}_{3}\left(3,5-(\mathrm{OMe})_{2}\right)$ (C2I, Prestwick Chemicals). For drug post-treatment, chemicals were applied $30 \mathrm{~min}$ after BDNF application.

For induction of chemical LTP, slices were transferred to a modified aCSF containing the following (in mM): $\mathrm{NaCl} 124, \mathrm{KCl} 5, \mathrm{CaCl}_{2} 5, \mathrm{MgCl}_{2}$ $0.1, \mathrm{KH}_{2} \mathrm{PO}_{4} 1.25, \mathrm{NaHCO}_{3} 24$, D-glucose 10, and tetraethylammonium (TEA) 25 for $10 \mathrm{~min}$, and transferred back to normal aCSF. For drug post-treatment, chemicals were applied $5 \mathrm{~min}$ after changing the medium back to normal aCSF.

Intrahippocampal injections of antisense olygodeoxinucleotides (asODN). Adult male Sprague Dawley rats (2-3 months of age) were anesthetized and subjected to bilateral hippocampal surgeries $(4.3 \mathrm{~mm}$ posterior to bregma; $2.5 \mathrm{~mm}$ lateral from midline; $2.5 \mathrm{~mm}$ ventral), as described previously (Guzowski et al., 2000; Garcia-Osta et al., 2006). RhoA asODN was a 16-mer (5'-TCCTGATGGCAGCCAT-3') directed against initiation of the translation site of the rat RhoA mRNA sequence (Torsoni et al., 2005). Scrambled ODN sequence (5'-GTGCCGG TTACCATCA- $3^{\prime}$ ) was designed using the siRNA Wizard, version 3.1 web tool (http://www.sirnawizard.com). All bases were phosphorothioateprotected and obtained from Integrated DNA Technologies. The asODN $(1 \mu \mathrm{l}, 500 \mu \mathrm{M})$ was injected into one hippocampus and the scrambled ODN into the contralateral hippocampus. One hour after injection, hippocampal slices within $400 \mu \mathrm{m}$ of the injection site were prepared for electrophysiological experiments. Electrophysiological experiments were performed blindly to ODN injection groups.

Electrophysiology. After dissection, hippocampal transversal slices (350 $\mu \mathrm{m}$ thick) were transferred to an interface recording chamber and exposed to a warm, humidified atmosphere of $95 \% \mathrm{O}_{2} / 5 \% \mathrm{CO}_{2}$ and continuously perfused with oxygenated and preheated $\left(33 \pm 0.5^{\circ} \mathrm{C}\right)$ aCSF at 1.4 $\mathrm{ml} / \mathrm{min}$. After $2 \mathrm{~h}$ incubation in the recording chamber, a single glass pipette filled with $2 \mathrm{~m} \mathrm{NaCl}$ was used to record field excitatory postsynaptic potentials (fEPSPs) elicited by stimulation of the Schaffer collateral pathway with twisted nichrome wires (single bare wire diameter, $50 \mu \mathrm{m})$ placed in CA1 stratum radiatum. Responses were recorded through a differential amplifier (DAM 50, World Precision Instruments) with a $10 \mathrm{kHz}$ high-pass and $0.1 \mathrm{~Hz}$ low-pass filter. Before each experiment, the input/output $(\mathrm{I} / \mathrm{O})$ relation was examined by varying the in- tensity of the stimulation. Paired-pulse facilitation was tested at 20-300 $\mathrm{ms}$ interval. LTP was induced by theta burst stimulation (TBS, 10 bursts of 4 pulses at $100 \mathrm{~Hz}$ delivered at $5 \mathrm{~Hz}$ ). Data were collected and digitized by Clampex, the slopes of fEPSP were measured, and data were expressed as means \pm SEM; statistical significance of differences between means was calculated with appropriate statistical tests, as indicated in figure legends.

In situ phalloidin labeling. Methods for analyzing actin polymerization were slightly modified from those described previously (Kramar et al., 2006). Rhodamine-phalloidin $(6 \mu \mathrm{M})$ was applied topically from a micropipette every $5 \mathrm{~min}$ for $20 \mathrm{~min}$ in slices that received low-frequency stimulation in the presence or absence of drugs or $25 \mathrm{~min}$ after the delivery of TBS. Slices were then collected and fixed in 4\% PFA for $1 \mathrm{~h}$, cryoprotected in $30 \%$ sucrose for $1 \mathrm{~h}$ at $4^{\circ} \mathrm{C}$, and sectioned on a freezing microtome at $20 \mu \mathrm{m}$. Labeling was examined using a Nikon C1 confocal laser-scanning microscope $(60 \times)$. Identification and measurement of labeled spines were performed on a $500 \mu \mathrm{m}^{2}$ sampling area within the zone of physiological recording as described previously (Kramar et al., 2006). Spine numbers in each image were analyzed with the ImageJ software. The threshold was set to count the numbers of punctas. Particles with sizes from 2 to 100 pixels were counted in each field.

Immunohistochemistry. Immunohistochemistry was performed in 30 $\mu \mathrm{m}$ frozen sections from acute hippocampal slices as described previously (Wang et al., 2014). Primary antibodies were as follows: rabbit anti-RhoA (1:50, sc-179) and mouse anti-PSD95 (1:500, MA1-045, Thermo Scientific), or mouse anti-RhoA (1:50) and rabbit anti-PSD95 (1:1000, ab18258, Abcam). Secondary antibodies were as follows: AlexaFluor-594 goat anti-rabbit IgG (A-11037, Invitrogen) and AlexaFluor-488 goat anti-mouse IgG (A-11001). Immunostained slices were examined under a Nikon Eclipse TE2000 confocal fluorescence microscope using EZ-C1 software. Quantification of dendritic punctas was performed using ImageJ software by counting the number of particles $(2-100$ pixels) per field $(4 \times$ amplification from $100 \times$ objective using $150 \mu \mathrm{m}$ of pinhole aperture and $512 \times 512$ pixels of resolution). Colocalization analysis was performed using "Just another Colocalisation plugin" (Bolte and Cordelières, 2006) under ImageJ software, and results were expressed as normalized ratios of RhoA-positive punctas colocalized with PSD95-positive punctas over total PSD95-positive punctas (M1 coefficient).

Metabolic labeling of synaptoneurosomes and immunoprecipitation. Detection of de novo protein synthesis was determined by using metabolic labeling of cortical synaptoneurosomes with Click-iT L-azidohomoalanine (AHA) (Invitrogen), as previously described (Wang et al., 2014), with minor modifications. Briefly, after treatment of synaptoneurosomes in the presence of AHA $(500 \mu \mathrm{M})$ and subsequent biotin conjugation, equal amounts of proteins $(\sim 5 \mathrm{mg} / \mathrm{ml})$ were incubated with a mouse monoclonal RhoA antibody ( $1: 10$, sc- 418 , Santa Cruz Biotechnology) overnight at $4^{\circ} \mathrm{C}$. Subsequently, $50 \mu \mathrm{l}$ of protein A-Sepharose beads (1:1 slurry, Sigma) was added to each sample and incubated for $1 \mathrm{~h}$ at $4^{\circ} \mathrm{C}$ with gentle rocking. After three washes, samples were processed for SDSPAGE and Western blots (see below). IRDye 800CW streptavidin (1: 2000, LI-COR Biosciences) was used to detect biotin-conjugated (newly synthesized) RhoA. Rabbit polyclonal anti-RhoA antibody (1:200, sc179, Santa Cruz Biotechnology) was used to detect total immunoprecipitated RhoA.

Actin polymerization assay. Actin polymerization was quantified by measurement of "rhodamine-phalloidin fluorescent enhancement," as previously described (Briz and Baudry, 2014). In brief, hippocampal slices (3-6 pooled slices) were washed twice with fresh aCSF after treatments and subsequently fixed in PBS containing 4\% PFA and 1\% octyl$\beta$-D-glucopyranoside for $15 \mathrm{~min}$ at room temperature. After two rinses with PBS, slices were homogenized and centrifuged at $1000 \times g$ for $1 \mathrm{~min}$. Lysates were incubated with $15-30 \mathrm{~nm}$ phalloidin-TRITC (Invitrogen) for 30-45 $\mathrm{min}$ at room temperature. After 3 washes, lysates were collected in $200 \mu \mathrm{l} /$ slice of PBS, and fluorescent intensity (excitation and emission wavelength were 546 and $590 \mathrm{~nm}$, respectively) was determined using a POLARstar Omega fluorescence polarization microplate reader (BMG Laboratory). 
RhoA activity assay. RhoA activity was determined by pull-down of RhoA-GTP with Rhotekin binding domain-linked agarose beads (Millipore), as described previously (Rex et al., 2009), with little modifications. Briefly, samples (6-10 pooled slices) were homogenized in $\mathrm{Mg}^{2+}$ lysis buffer (25 mм HEPES, pH 7.5, $150 \mathrm{~mm} \mathrm{NaCl}$, 1\% Igepal CA-630, $10 \mathrm{~mm}$ $\mathrm{MgCl}_{2}, 0.5 \mathrm{~mm}$ EDTA, and $10 \%$ glycerol) containing a protease inhibitor mixture (Thermo Scientific). Protein levels were measured and equalized. Samples were incubated with Rhotekin binding domain-agarose beads and gently rocked for $1 \mathrm{~h}$ at $4^{\circ} \mathrm{C}$. Agarose beads were collected by centrifugation $\left(30 \mathrm{~s}, 16,000 \times g, 4^{\circ} \mathrm{C}\right)$ and washed three times with $\mathrm{Mg}^{2+}$ lysis buffer, resuspended and boiled in Laemmli buffer (containing 50 $\mathrm{mm}$ dithiothreitol) for $5 \mathrm{~min}$, and then separated by SDS-PAGE. Western blot analysis was performed using anti-RhoA antibody (sc-418). GTP and GDP loading controls were incubated with $100 \mu \mathrm{M}$ GTP- $\gamma \mathrm{S}$ or $1 \mathrm{~mm}$ GDP for $30 \mathrm{~min}$ at $30^{\circ} \mathrm{C}$.

Western blot. Protein lysates were prepared at a final concentration of $4-8 \mu \mathrm{g}$ of protein/ $\mu \mathrm{l}$ by homogenization of rat hippocampal slices or cortical synaptoneurosomes in ice-cold lysis buffer $(50 \mathrm{~mm}$ Tris- $\mathrm{HCl}, \mathrm{pH}$ 7.4, 1\% Triton, 1 mм EDTA, 1 mм EGTA, 1 mm PMSF), containing a protease and phosphatase inhibitor mixture (Thermo Scientific). After sample processing, 20-40 $\mu \mathrm{g}$ of denatured proteins were subjected to $10-15 \%$ SDS-PAGE, as previously described (Briz and Baudry, 2014). The following primary antibodies were used: anti-RhoA antibody (1:200, sc-418), anti-phospho-cofilin (1:1000, ab12866, Abcam), anti-cofilin (1: 1000, \#5175, Cell Signaling Technology), anti-phospho-PAK1/2/3 (1: 1000, 44940, Invitrogen), anti-PAK3 (1:500, 06-902, Millipore), antiLIMK1 (1:1000,\#3842), and anti-actin (1:10,000; MAB1501, Millipore).

Statistical analysis. Unless otherwise indicated, results were generally calculated as means \pm SEM from at least three independent experiments. The number of independent experiments $(n)$ usually refers to the number of animals used; for Western blots, $n$ refers to the number of slices obtained from at least three different animals; for quantification of immunostaining, $n$ refers to the number of fields analyzed in at least two or three slices from three or more different animals. For experiments where only two groups were compared, two-tailed $t$ test was used to determine statistical significance. When $>2$ groups were compared, one-way or two-way ANOVA followed by Bonferroni post-test analysis was used.

\section{Results \\ BDNF-mediated actin polymerization in hippocampal slices involves activation of the RhoA/ROCK/cofilin pathway}

We first studied the temporal profile of BDNF-induced regulation of actin cytoskeleton reorganization in acute hippocampal slices, as BDNF was previously reported to regulate cytoskeletal modifications occurring during LTP (Rex et al., 2007). Bath application of BDNF $(100 \mathrm{ng} / \mathrm{ml})$ caused a biphasic, time-dependent stimulation of actin cytoskeletal dynamics; a rapid (but not significant) increase in actin polymerization was found 5 min after BDNF treatment, a return to baseline by $15 \mathrm{~min}$, followed by a second increase at $30 \mathrm{~min}$, which again decayed by $60 \mathrm{~min}$ after BDNF treatment (Fig. 1A). We repeated the time course study using TEAinduced chemical LTP (Hanse and Gustafsson, 1994). In contrast to BDNF, TEA produced a rapid and sustained stimulation of actin filament dynamics, which lasted up to $30 \mathrm{~min}$ with a return to baseline by $60 \mathrm{~min}$ after induction of chemical LTP (Fig. 1B).

Hippocampal LTP involves cofilin inactivation by phosphorylation at Ser3 (Fukazawa et al., 2003). We compared the effects of BDNF on cofilin phosphorylation and actin polymerization at different times in hippocampal slices. BDNF treatment increased cofilin phosphorylation within $5 \mathrm{~min}$, but the effect did not reach statistical significance. Instead, BDNF-mediated cofilin phosphorylation was more robust at 30 and $60 \mathrm{~min}$ (Fig. 1C). A similar temporal profile was found for BDNF-induced RhoA activation (Fig. 1D), as determined by pull-down assays of active (GTPbound) RhoA. RhoA activity slightly increased (although not significantly) $5 \mathrm{~min}$ after BDNF treatment; this was followed by transient stimulation of RhoA at $30 \mathrm{~min}$, which returned to control levels $60 \mathrm{~min}$ after BDNF treatment (Fig. 1D). Interestingly, the total levels of RhoA also increased at $15 \mathrm{~min}$, which could explain the decrease in RhoA-GTP/RhoA ratio at this time point. In any event, the increase in RhoA activity temporally matched the rise in cofilin phosphorylation and the stimulation of actin polymerization.

We next determined the effects of TEA and BDNF on PAK phosphorylation, a protein kinase downstream of both Cdc42 and Rac, which has been linked to cofilin-mediated regulation of the actin cytoskeleton during LTP (Chen et al., 2007). In agreement with those findings, TEA-induced LTP was associated with PAK activation in hippocampal slices at 5-15 $\mathrm{min}$, and the effect was lost by 30-60 min (Fig. $1 F$ ). Similarly, BDNF increased PAK phosphorylation at 15-30 min but not at $60 \mathrm{~min}$ (Fig. 1E).

To analyze which signaling pathway(s) was(were) involved in the effects of TEA and BDNF on actin filament dynamics, we pretreated hippocampal slices either with a ROCK-specific inhibitor (H1152, $200 \mathrm{nM})$ or a potent and isoform-selective PAK inhibitor (PF-3758309). Two concentrations of PF-3758309 were used ( 50 and $500 \mathrm{nM}$ ), based on its different affinities for PAK1/4 versus PAK2/3 isoforms (Murray et al., 2010). Stimulation of PAK phosphorylation by TEA was significantly prevented by PF3758309 , but the effect was statistically significant only at the highest concentration (Fig. $1 G$ ). Similar results were obtained with this inhibitor on BDNF-induced PAK activation in a previous study (Briz and Baudry, 2014). TEA-induced actin polymerization was also completely blocked by PF-3758309 (at both concentrations) as well as by the ROCK inhibitor (Fig. $1 H$ ). In contrast, BDNF-mediated stimulation of actin polymerization at $30 \mathrm{~min}$ (time at which both pathways were activated) was suppressed by H1152, but not by PF-3758309 (Fig. $1 H$ ). These results indicate that BDNF-mediated regulation of actin cytoskeleton involves activation of the RhoA/ROCK pathway only, whereas TEA-mediated actin polymerization involves stimulation of both RhoA/ROCK and Rac/PAK signaling.

\section{BDNF rapidly stimulates dendritic RhoA synthesis in CA3 and CA1 through an mTOR-dependent mechanism}

RhoA has been reported to be rapidly upregulated in response to $\mathrm{BDNF}$ and other signaling factors in cultured neurons and in synaptoneurosomes (Wu et al., 2005; Troca-Marín et al., 2010). Our data with the RhoA activity assay suggested that BDNF could also modulate RhoA levels in hippocampal slices (Fig. 1C). To confirm this, we repeated the time course study in hippocampal slices and determined RhoA protein levels by Western blot. BDNF treatment caused a modest but significant increase in RhoA protein levels at $30 \mathrm{~min}$, which returned to control levels by $60 \mathrm{~min}$ (Fig. 2A). TEA produced a similar transient elevation of RhoA protein levels with a peak at $15 \mathrm{~min}$ and a return to basal levels by $30 \mathrm{~min}$ (Fig. 2B).

We next performed a series of experiments using different protein synthesis inhibitors to determine whether the observed changes in RhoA levels involved de novo protein synthesis. Pretreatment of hippocampal slices with either rapamycin $(1 \mu \mathrm{M})$ or the general translation inhibitor cycloheximide $(25 \mu \mathrm{M})$ completely suppressed the increase in RhoA levels induced by BDNF (Fig. 2C). Dendritic protein translation has also been shown to be dependent on the extracellular-regulated kinase (ERK) pathway during LTP (Panja et al., 2009; Chotiner et al., 2010). Preapplication of the ERK inhibitor U0126 (5 $\mu \mathrm{M})$ reduced the effects of BDNF on RhoA levels, but the effect was not statistically significant (Fig. 2C). 
A

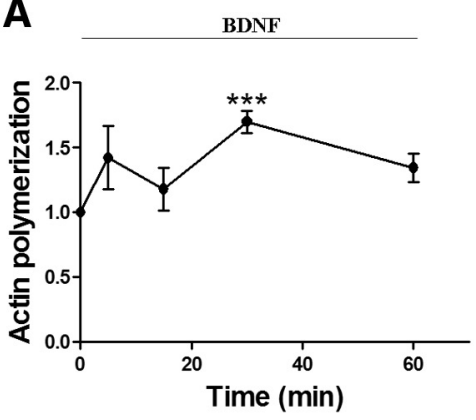

D
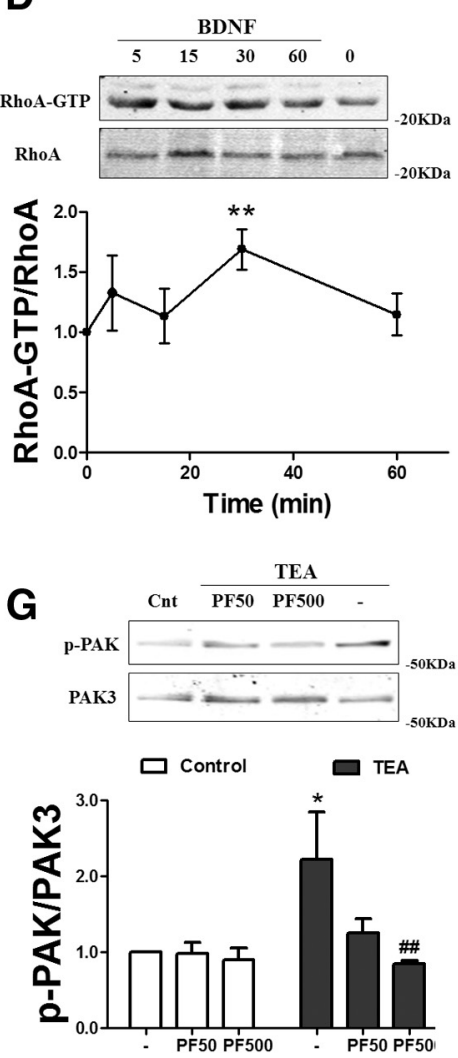

B TEA

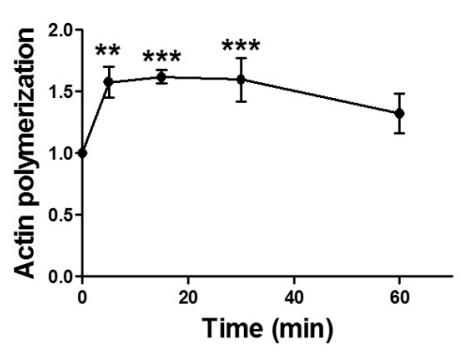

E
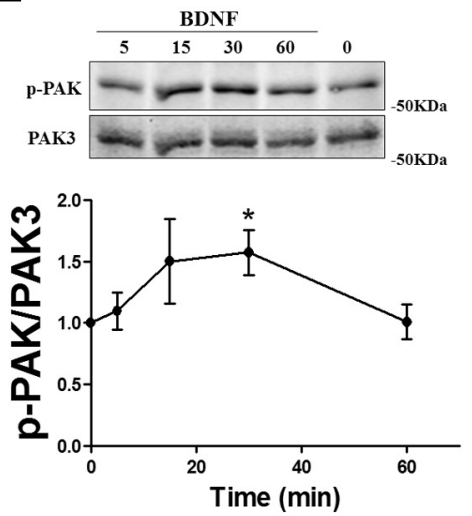

H
C
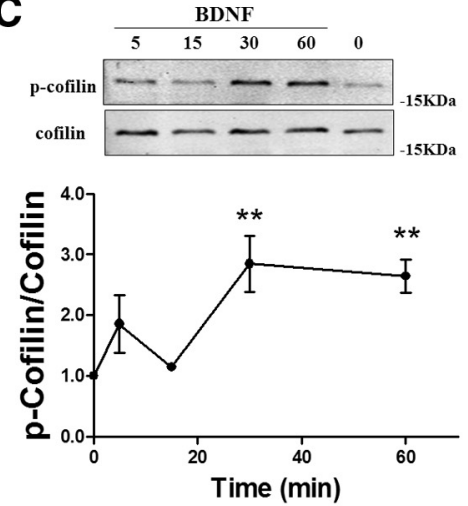

F
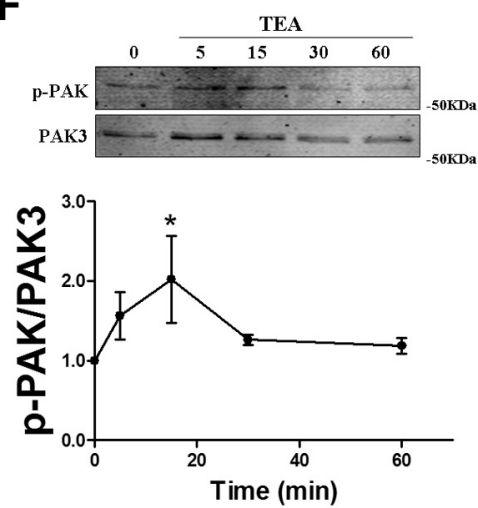

Figure 1. Time course for BDNF- and TEA-stimulated actin signaling and cytoskeletal dynamics in hippocampal slices. BDNF $(\boldsymbol{A})$ or TEA (B) was applied to hippocampal slices for the indicated periods of time, and slices from different experimental groups were collected at the same time. Data are presented as phalloidin fluorescence values normalized to control: $\boldsymbol{A}, n=4-14 ; \boldsymbol{B}, n=$ 3-10. C-F, Immunoblots (top) and quantitative analysis (bottom) for BDNF-induced cofilin phosphorylation (C), RhoA activation (D), and PAK phosphorylation (E), and for TEA-induced PAK phosphorylation. Data are presented as the ratio (fold of control) of the following: (C) phospho-cofilin (p-cofilin) over total cofilin $(n=3),(\boldsymbol{D})$ RhoA-GTP over total RhoA ( $n=4-10)$, $(\boldsymbol{E})$ phospho-PAK (p-PAK) over total PAK3 ( $n=4-8)$, and $(\boldsymbol{F})$ p-PAK over total PAK3 ( $n=3-7)$. $\boldsymbol{G}, \boldsymbol{H}$, Effects of R0CK (H11, 200 nm) and PAK (PF, $50-500$ nm) inhibitors on TEA-induced PAK phosphorylation $(\boldsymbol{G})$ and on BDNF- or TEA-induced actin polymerization $(\boldsymbol{H})$. Data are presented as follows: $\boldsymbol{G}$, ratio (fold of control) of p-PAK over total PAK3 ( $n=3-5$ ); or $\boldsymbol{H}$, phalloidin fluorescence values normalized to control $(n=3-5)$. ${ }^{*} p<0.05,{ }^{* *} p<0.01,{ }^{* * *} p<0.001$ versus control; ${ }^{\#} p<0.05,{ }^{\# \#} p<0.01$ versus TEA or BDNF alone (one- or two-way ANOVA).

To further confirm that RhoA was newly synthesized in response to BDNF we performed metabolic labeling in cortical synaptoneurosomes using a modified amino acid AHA, which is incorporated into newly translated proteins. We have previously shown that this technique sensitively detected nascent proteins (Wang et al., 2014). Consistent with previous findings using autoradiography (Wu et al., 2005; Troca-Marín et al., 2010), treatment of synaptoneurosomes with BDNF for 30 min significantly increased the levels of de novo synthesized RhoA compared with control. This effect was also blocked by rapamycin and cycloheximide (Fig. 2E,F).

RhoA mRNA has been detected in the CA1 neuropil layer as well as in growth cones and synaptoneurosomes (Wu et al., 2005; Troca-Marín et al., 2010; Cajigas et al., 2012). The above results suggest that activity-dependent RhoA synthesis takes place in dendrites, where protein synthesis occurs during synaptic plasticity and memory formation (Sutton and Schuman, 2006). To test this hypothesis, we compared changes in RhoA protein levels in hippocampal dendritic spines with those of the postsynaptic marker, postsynaptic density 95 (PSD95), by using double immunohistochemistry. Under control conditions, RhoA immunostaining was predominantly found in cell nuclei, as revealed by colocalization with the nuclear dye DAPI, with weak staining in dendritic processes in area CA1 of hippocampus (Fig. $3 A, C$ ). Treatment with BDNF for 30 min enhanced RhoA immunofluorescence intensity in CA1 stratum radiatum (Fig. $3 A, C, D$ ) as well as its colocalization with PSD95 (Fig. $3 F, G$ ). These effects were completely suppressed in slices preincubated with rapamy- 

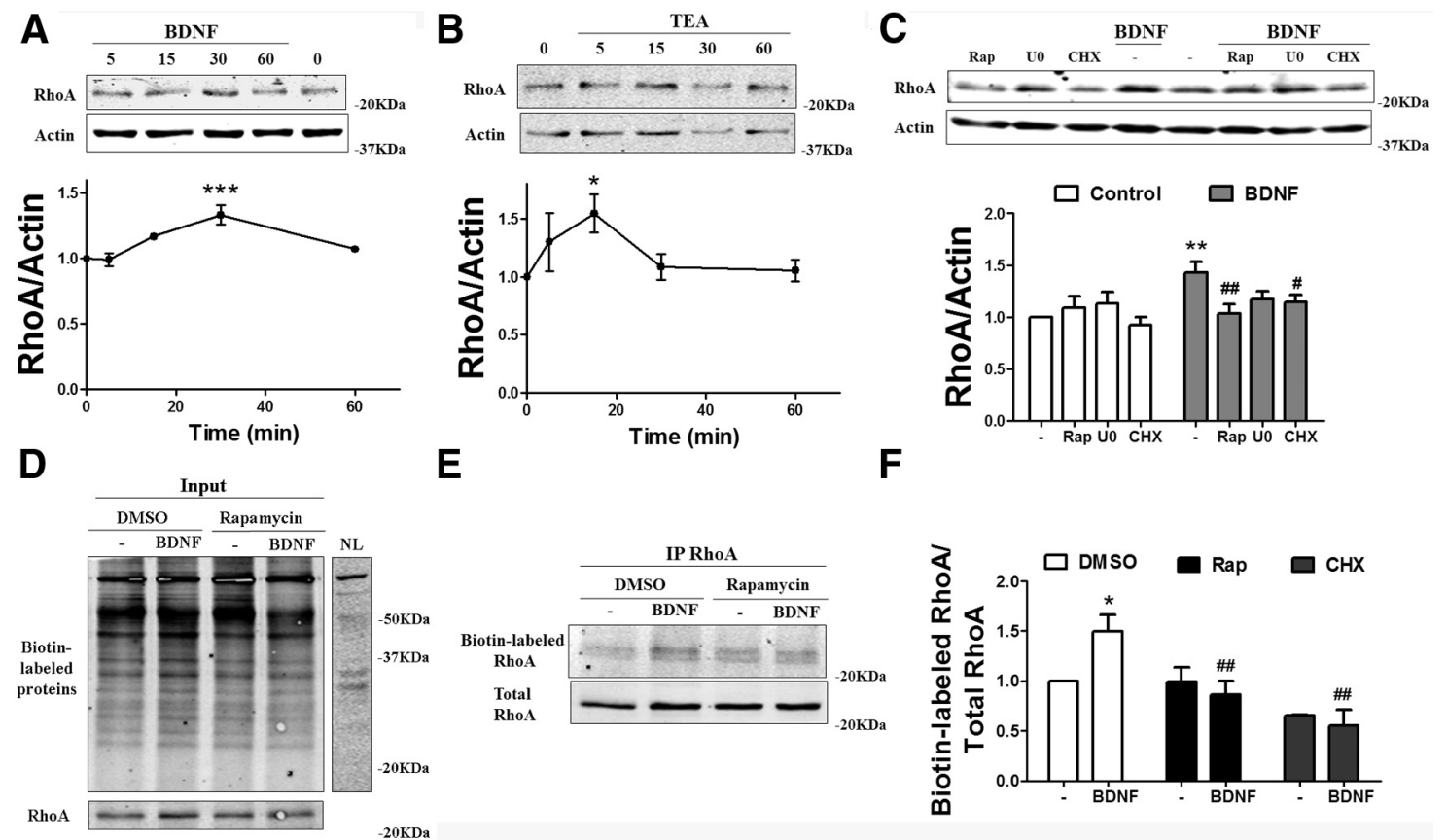

$\mathbf{E}$

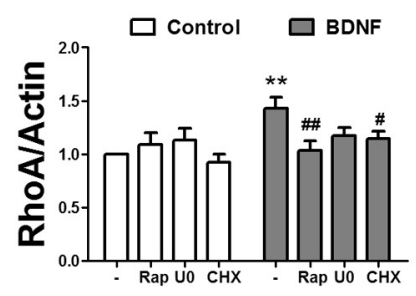

$\mathbf{F}$
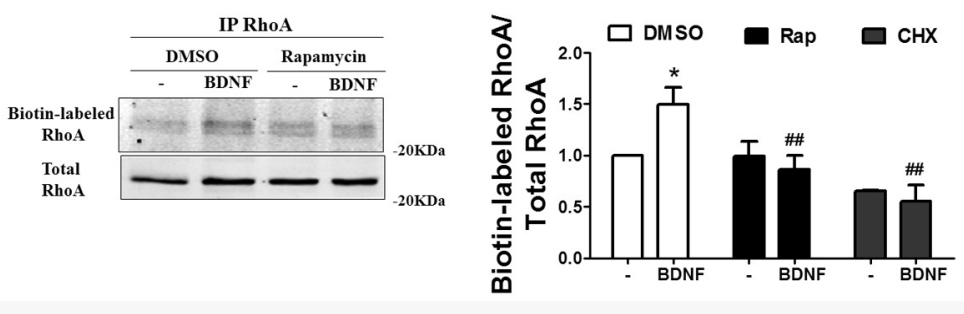

Figure 2. BDNF stimulates de novo RhoA synthesis via mTOR signaling. Time course for BDNF- $(\boldsymbol{A})$ or TEA-induced $(\boldsymbol{B})$ increase of RhoA protein levels in hippocampal slices. Data are presented as the ratio (fold of control) of RhoA over actin $(n=3-10)$. C, BDNF-induced increase of RhoA protein levels is blocked by protein synthesis inhibitors. Hippocampal slices were pretreated with DMSO $(-)$, rapamycin (Rap, $1 \mu \mathrm{M}), \mathrm{U} 0126(\mathrm{UO}, 5 \mu \mathrm{M})$, or cycloheximide (CHX, $25 \mu \mathrm{M})$ for $30 \mathrm{~min}$ and then incubated with BDNF for an additional 30 min. Data are presented as the ratio of RhoA over actin $(n=11-13) . \boldsymbol{F}$, Metabolic labeling of RhoA in synaptoneurosomes. Synaptoneurosomes were incubated with BDNF for 30 min in the absence (nonlabeled [NL]) or presence of $\mathrm{L}-\mathrm{AHA}$ (500 $\mu \mathrm{M})$. Samples were then analyzed by Western blot, and proteins were detected by IRDye $800 \mathrm{CW}$ streptavidin before $(\boldsymbol{D})$ or after $(\boldsymbol{E})$ immunoprecipitation with RhoA antibody. $\boldsymbol{F}$, Quantification of immunoblots from $\boldsymbol{E}$; data are presented as the ratio (fold of control) of biotin-labeled RhoA (both bands were quantified together) over total RhoA $(n=2-7) .{ }^{*} p<0.05$, ${ }^{* *} p<0.01$, ${ }^{* * *} p<0.001$ versus control; ${ }^{\#} p<0.05,{ }^{\# \#} p<0.01$ versus BDNF alone (one- or two-way ANOVA).

cin (Fig. $3 A, C, D)$. BDNF also increased PSD95 immunofluorescence, but the effect was not blocked by rapamycin (Fig. 3C,E). Notably, somatic RhoA immunostaining was not affected by BDNF (Fig. 3B), indicating that BDNF effects on RhoA levels are restricted to dendrites. To further analyze the effects of BDNF on RhoA subcellular distribution, we quantified RhoA immunostaining in dendritic spines from CAl using a different RhoA antibody; as opposed to the one used previously (sc-179, polyclonal), this monoclonal antibody (sc-418) did not stain nuclei or dendritic shaft. Instead, it exhibited a punctate pattern with staining in dendritic spines, as evidenced by its partial colocalization with PSD95 (Fig. 3H), a result in good agreement with a previous study using the same antibody in which RhoA staining was found in dendritic spines (where it colocalized with F-actin) but not in the nucleus of cultured neurons (Schubert et al., 2006). BDNF treatment significantly increased both the size and the number of puncta-positive for RhoA, compared with control (Fig. 3I,J). Similar results were obtained in the CA3 area of hippocampus. In contrast, BDNF did not enhance dendritic RhoA immunostaining in the dentate gyrus (Fig. 3I,J). Overall, these results confirm that RhoA is rapidly translated in hippocampal dendritic spines in response to BDNF.

\section{Activity-dependent actin polymerization and LTP consolidation require de novo RhoA synthesis}

We next investigated the role of RhoA synthesis on BDNFinduced activation of the RhoA/ROCK/cofilin pathway and cytoskeletal reorganization. Preincubation of hippocampal slices with rapamycin suppressed the increase in RhoA-GTP elicited by BDNF (Fig. 4A). Similarly, BDNF-induced cofilin phosphorylation was totally blocked in the presence of either rapamycin or cycloheximide (Fig. 4B). Consistently, stimulation of actin po- lymerization by BDNF was completely abrogated by both protein synthesis inhibitors (Fig. 4C). The ERK inhibitor U0126 attenuated the effect of BDNF on cofilin phosphorylation and actin polymerization, but the effect was only statistically significant for the former (Fig. $4 B, C$ ). In addition to RhoA, LIMK1 has also been reported to be upregulated in response to BDNF application in an mTOR-dependent mechanism (Schratt et al., 2006). Therefore, stimulation of LIMK1 translation by BDNF could also account for the requirement of protein synthesis in cofilin phosphorylation and actin polymerization. To explore this possibility, we determined LIMK1 levels in hippocampal slices at different time points after BDNF treatment or induction of chemical LTP. However, we did not detect any changes in LIMK1 levels up to $1 \mathrm{~h}$ with either treatment (data not shown). The above results strongly suggest that RhoA translation is required for BDNFinduced stimulation of RhoA/ROCK/cofilin pathway and actin polymerization.

To further confirm that protein synthesis is necessary for activity-dependent cytoskeletal modifications, we performed in situ phalloidin staining in the CA1 area of hippocampus after TBS. As described previously (Rex et al., 2007, 2009), TBS produced a marked increase in phalloidin fluorescence in dendritic spines around the stimulating electrode under control conditions. In contrast, TBS failed to stimulate phalloidin staining in slices pretreated with rapamycin for $30 \mathrm{~min}$ (Fig. 4E,F). Rapamycin also blocked TBS-induced LTP consolidation in hippocampal slices (Fig. 4D), a result in good agreement with previous studies (Alarcon et al., 2004; Huang and Kandel, 2005).

These findings indicate that mTOR-dependent protein synthesis is necessary for TBS-induced reorganization of the actin cytoskeleton within dendritic spines. However, they do not provide direct evidence that RhoA translation is indeed required for 
A

A

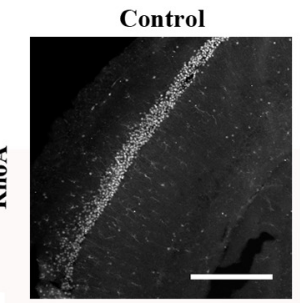

C
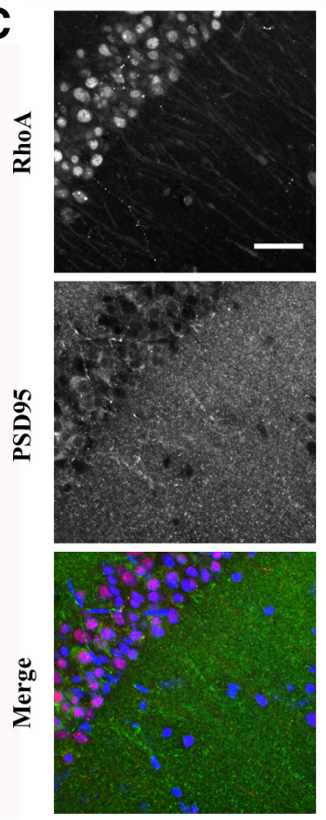

G
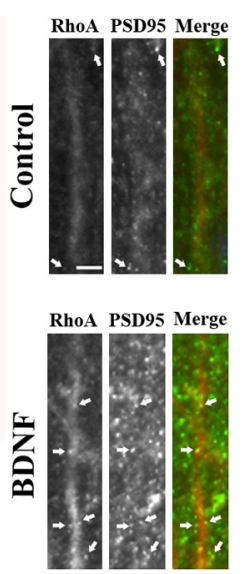

H

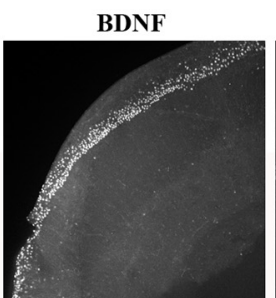

BDNF+Rapamycin
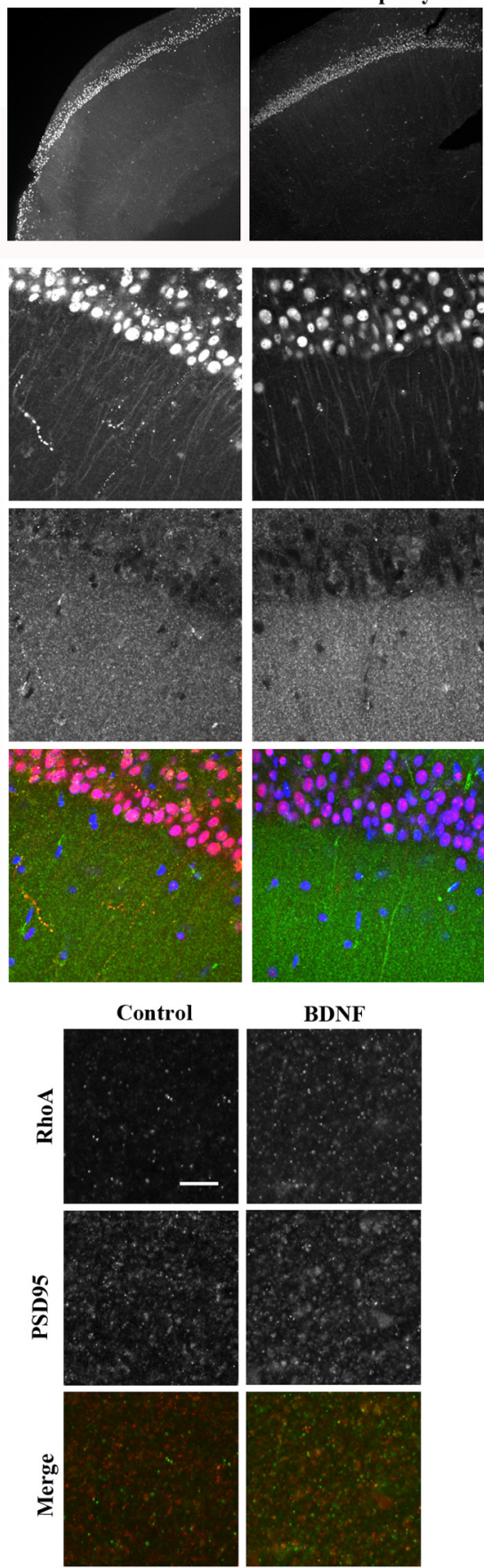
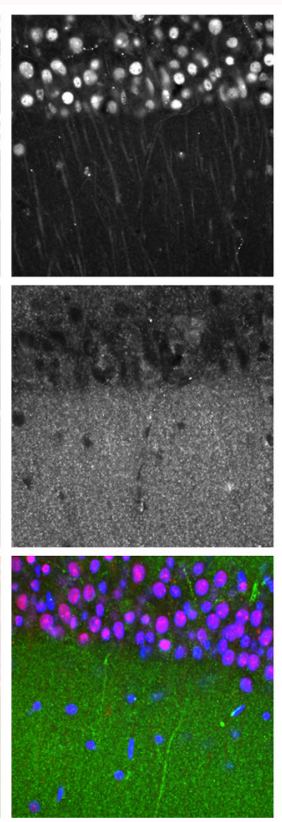

BDNF

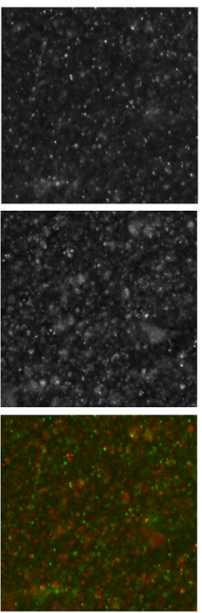

B

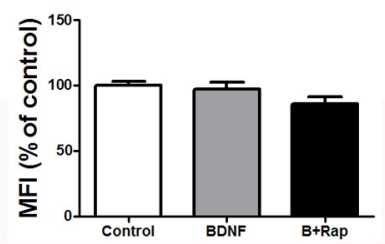

D

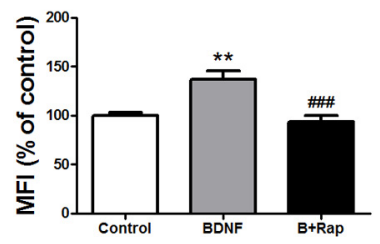

E

F
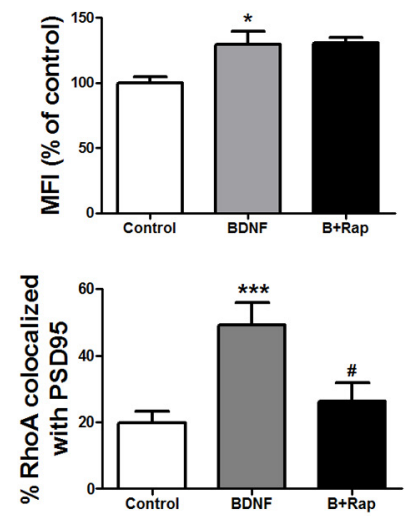

I

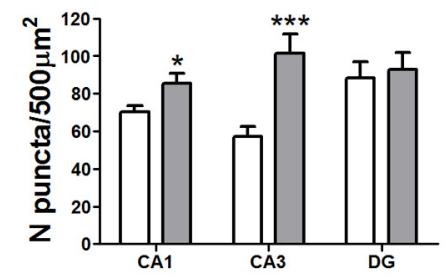

J

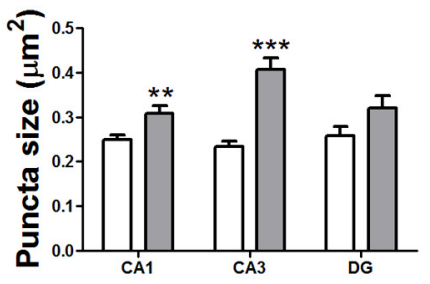

Figure 3. BDNF stimulates dendritic RhoA immunostaining in the CA1 and CA3 areas of hippocampus. Hippocampal slices were incubated in the absence (control) or presence of BDNF for 30 min without or with rapamycin (B+Rap). Representative images $(\boldsymbol{A})$ and quantification of MFI ( $\boldsymbol{B})$ of RhoA immunostaining in the somatic field of CA1 $(n=7-14)$. Scale bar, $400 \mu \mathrm{m}$. $\boldsymbol{C}$, Representative images of slices double-stained for RhoA (red) and PSD95 (green) along with DAPI (blue). Scale bar, $40 \mu \mathrm{m}$. D, E, Quantification of mean fluorescence intensity (MFI) of RhoA (D) and PSD95 (E) immunostaining determined in a $212 \times 212 \mu \mathrm{m}^{2}$ area in the dendritic field of CA1. ${ }^{*} p<0.05,{ }^{* *} p<0.01$ versus control; ${ }^{\# \# \#} p<0.001$ versus BDNF alone ( $n=9-18$, one-way ANOVA). $\boldsymbol{F}$, Percentage of RhoA-positive punctas colocalized with PSD95 (M1 coefficient). ${ }^{* * *} p<0.001$ versus control; ${ }^{*} p<0.05$ versus BDNF alone $(n=8-19$; one-way ANOVA). G, High-magnification images of dendrites from CA1 double-stained for RhoA (red) and PSD95 (green). Scale bar, $4 \mu \mathrm{m}$. Arrows indicate dendritic spines double-labeled with RhoA and PSD95. $\boldsymbol{H}$, High-magnification images from CA1 stratum radiatum double-stained for RhoA (green) and PSD95 (red) using a different RhoA antibody (sc-418). Scale bar, $20 \mu \mathrm{m}$. $\boldsymbol{I}, \boldsymbol{J}$, Quantification of density $(\boldsymbol{H})$ and size $(\boldsymbol{I})$ of RhoA-positive punctas in CA1, CA3, and dentate gyrus (DG). ${ }^{*} p<0.05,{ }^{* *} p<0.01,{ }^{* * *} p<0.001$ versus control $(n=11-28$, two-tailed $t$ test).

activity-dependent synaptic plasticity. To address this question, asODN directed against the initiation of the translation site of RhoA were stereotactically injected into dorsal CA1. Scrambled ODN were injected into the contralateral hippocampus as control (Fig. 5A). One hour after injection, hippocampal slices around the injection site were collected and incubated for an- other $2 \mathrm{~h}$, before analyzing features of synaptic transmission at Schaffer collateral-CA1 synapses, including input/output and paired-pulse facilitation. No significant difference was found in input/output response curve between the two groups (Fig. 5B); however, paired-pulse facilitation was increased after injection of RhoA asODN, compared with scrambled ODN (Fig. 5D). TBS- 

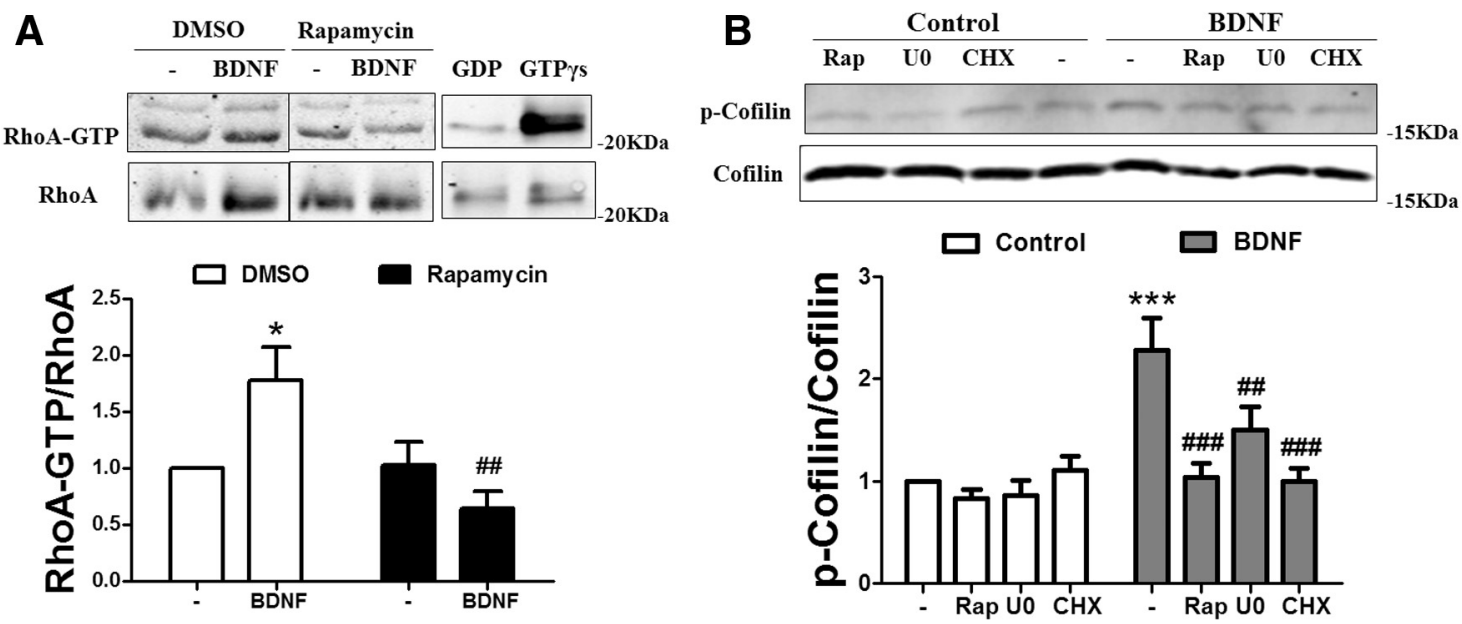

C
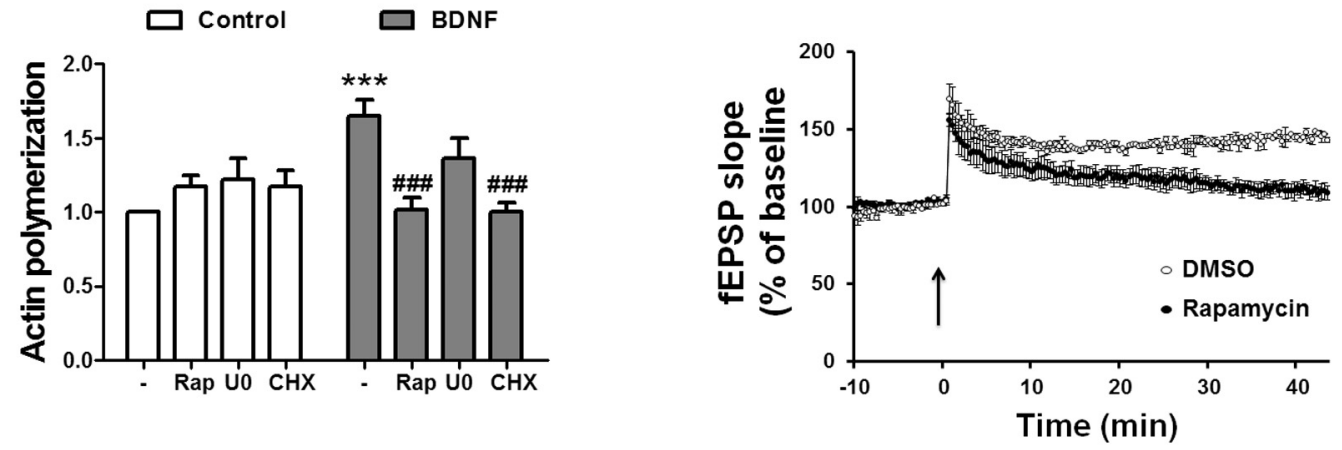

E
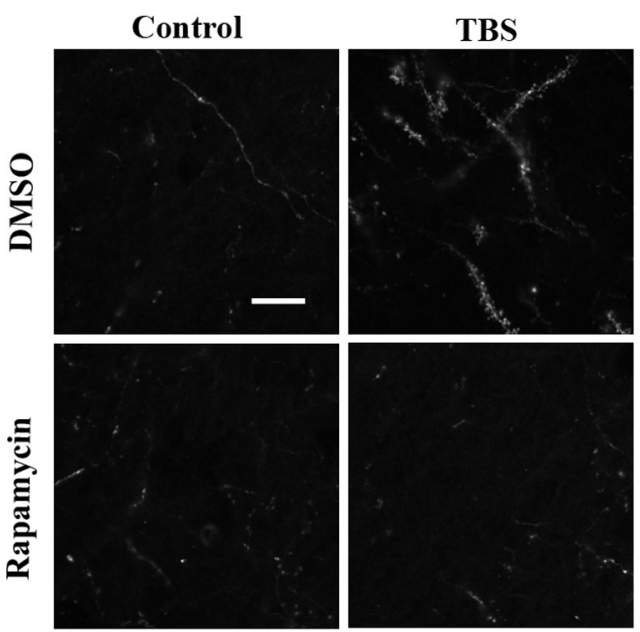

$\mathbf{F}$

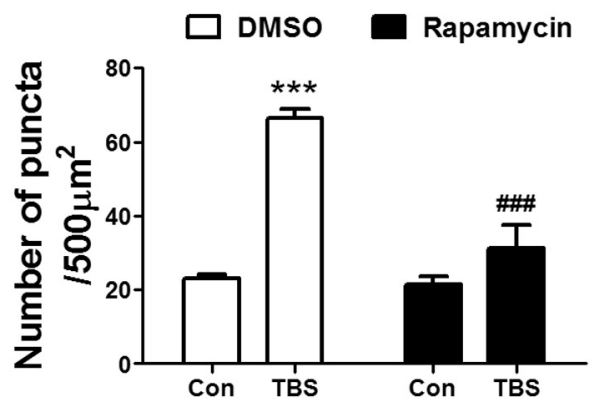

Figure 4. Activity-dependent actin polymerization and LTP consolidation are blocked by protein synthesis inhibitors. A-C, Effects of rapamycin (Rap, $1 \mu \mathrm{M}), \mathrm{U} 0126$ (U0, $5 \mu \mathrm{M})$, or cycloheximide $(C H X, 25 \mu \mathrm{M})$ on BDNF-induced RhoA activation $(\boldsymbol{A})$, cofilin phosphorylation $(\boldsymbol{B})$, and actin polymerization $(\boldsymbol{C})$ in hippocampal slices. Data are presented as the ratio (fold of control) of the following: (A) RhoA-GTP over total RhoA ( $n=3$ or 4), (B) p-cofilin over total cofilin $(n=5-11)$, or (C) phalloidin fluorescence values normalized to control ( $n=4$ or 5). $\boldsymbol{D}$, Rapamycin blocks LTP consolidation induced in field CA1 by TBS (black arrow). DMSO (open circles) or $1 \mu \mathrm{m}$ rapamycin (black circles) was applied for $10 \mathrm{~min}$ before TBS and throughout the whole recording period. Slopes of fEPSPs are expressed as percentage of the average values recorded during the $10 \mathrm{~min}$ baseline $(n=5)$. $\boldsymbol{E}$, Representative images of in situ phalloidin staining in CA1 25 min after TBS or no stimulation (control) in the absence (DMSO) or presence of rapamycin. $F$, Quantification of the density of dendritic spines labeled with phalloidin $(n=4-6)$. Scale bar, $40 \mu \mathrm{m} .{ }^{*} p<0.05$, ${ }^{* * *} p<0.001$ versus control; $\# p<0.01,{ }^{\# \#} p<0.001$ versus BDNF or TBS alone (two-way ANOVA).

induced LTP was impaired in hippocampal slices prepared from rats injected with RhoA asODN, whereas slices from rats receiving scrambled ODN exhibited normal LTP (Fig. 5C). Finally, an increase in both the size and the number of dendritic spines immunopositive for RhoA was found $15 \mathrm{~min}$ after delivery of TBS in slices from rats injected with scrambled ODN (Fig. $5 E-G$ ). In contrast, injection of RhoA asODN blocked TBS-induced increase in spine RhoA immunostaining without affecting RhoA basal levels (Fig. $5 E-G$ ). Together, these results indicate that de novo dendritic RhoA synthesis is a necessary step for LTP consolidation in area CA1 of hippocampus.

RhoA synthesis and degradation are regulated by different calpain isoforms

The transient synthesis of RhoA found in the present study in response to synaptic activity suggested that it is rapidly de- 
A

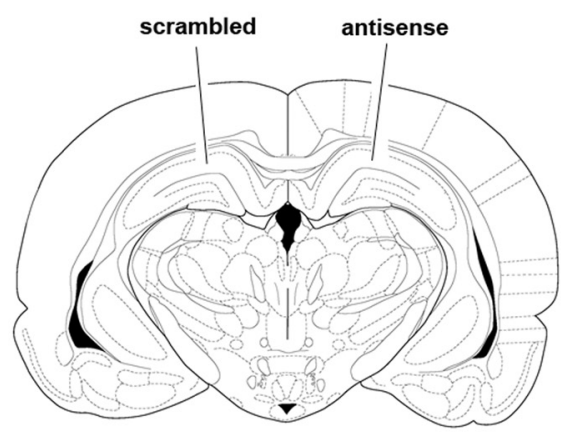

C

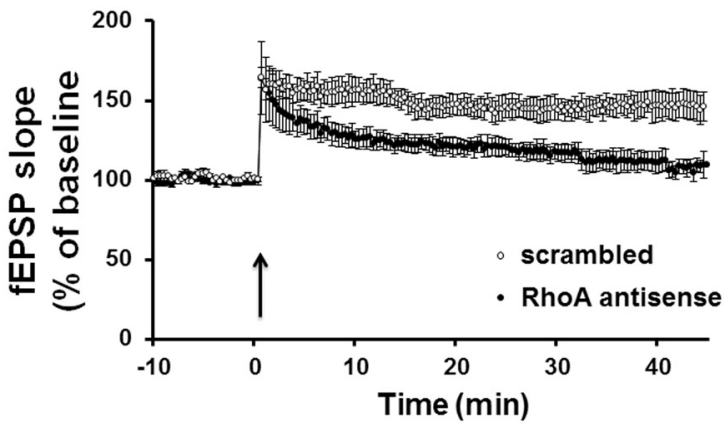

B

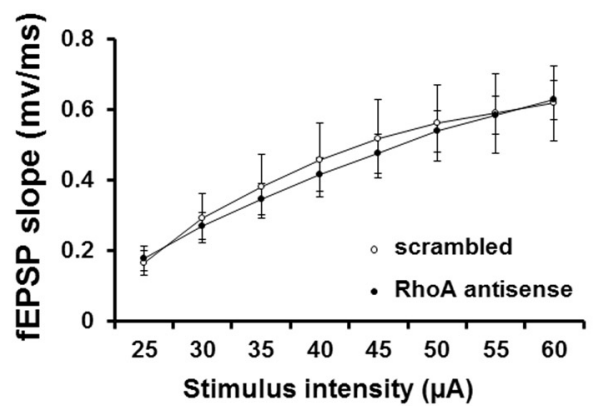

D

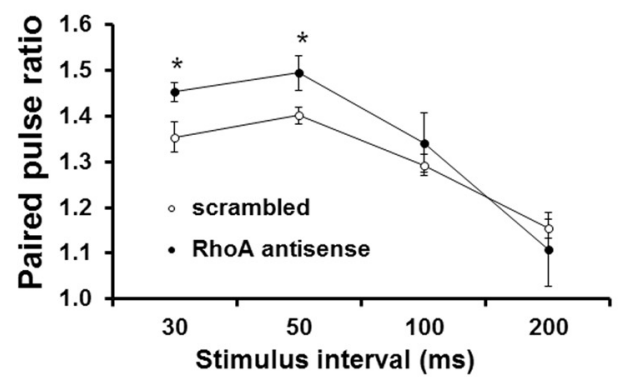

E

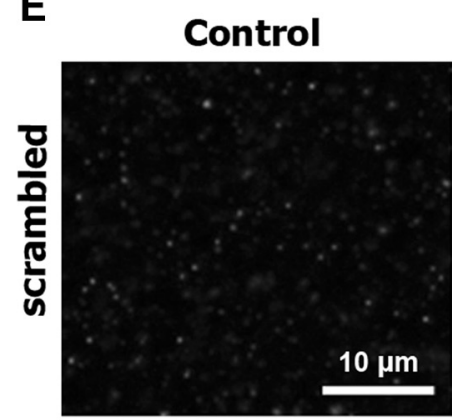

TBS
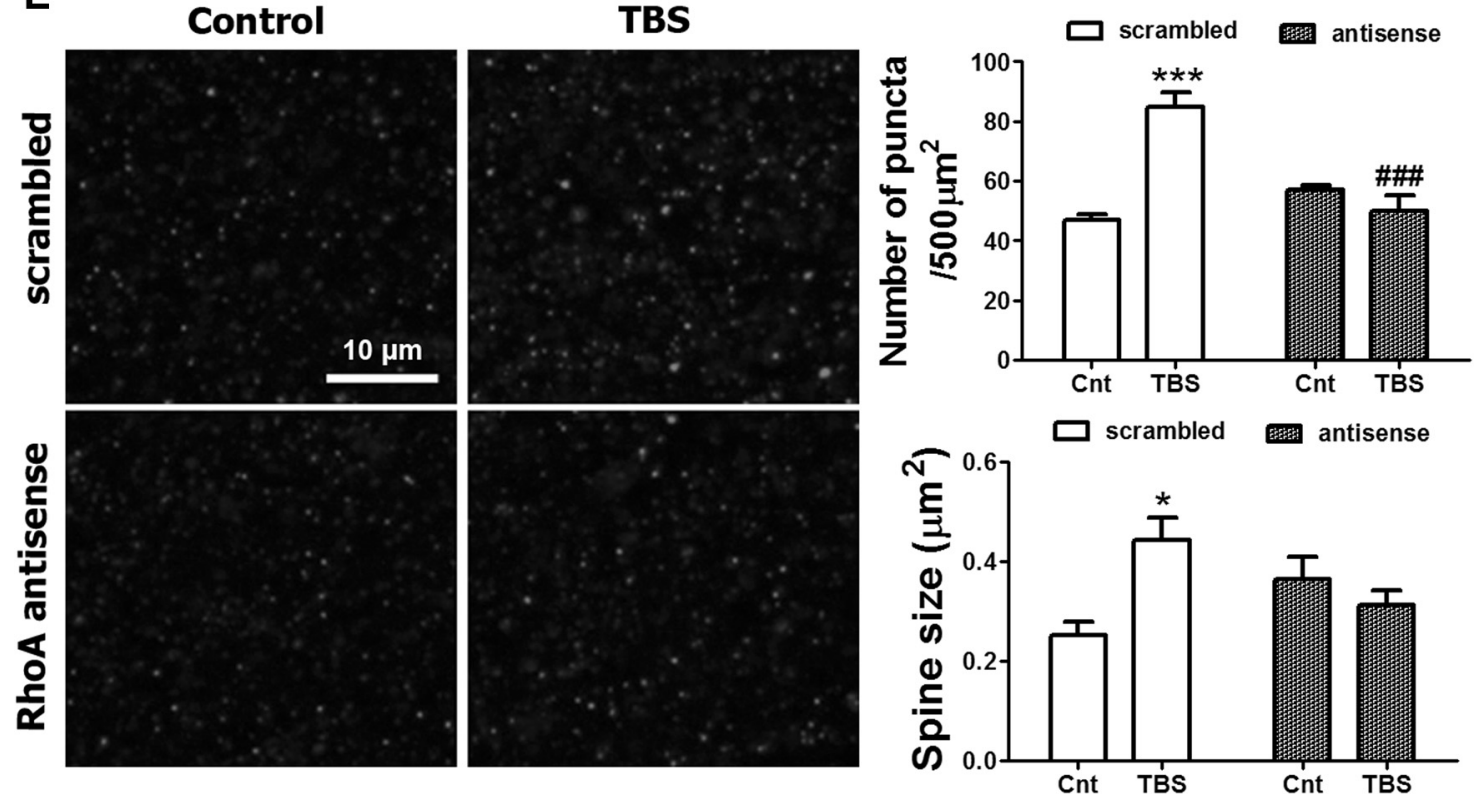

Figure 5. Intrahippocampal injection of RhoA antisense ODN in CA1 impairs LTP consolidation. $A$, Schematic representation of intrahippocampal injections of scrambled and RhoA as ODN in CA1. $\boldsymbol{B}$, Input/output response curves in hippocampal slices prepared from rats injected with either scrambled or RhoA asODN. Slopes of fEPSPs are expressed as mV/ms ( $n=4$ or 5 ). $\boldsymbol{C}$, RhoA asODN block LTP consolidation induced in field CA 1 by TBS (black arrow). Slopes of fEPSPs are expressed as percentage of the average values recorded during the 10 min baseline $(n=5)$. $D$, RhoA as $0 D N$ increase paired-pulse facilitation, represented as the ratio of the slope of the second response over that of the first response at the indicated time intervals between two consecutive stimuli $(n=6)$. ${ }^{*} p<$ 0.05 (two-way ANOVA). $\boldsymbol{E}$, Effect of RhoA antisense ODN injection on actin polymerization. Left: High-magnification images of dendritic spines stained with RhoA antibodies; right: quantification of the density (top) and size (bottom) of RhoA-positive puncta in control (Cnt) or 15 min after TBS. ${ }^{*} p<0.05,{ }^{* *} p<0.01$ versus control ( $n=3-5$, two-way ANOVA). Scale bar, $20 \mu \mathrm{m}$.

graded. We determined changes in RhoA levels in cortical synaptoneurosomes at different times after blockade of protein synthesis to estimate RhoA's half-life. Treatment with cycloheximide reduced RhoA levels ( $p=0.0029$, one-way ANOVA, $N=4-7$ ), and the decrease in RhoA levels as a function of time was fitted with a first-order reaction with a $\mathrm{t}_{1 / 2}$ of $\sim 30 \mathrm{~min}$, indicating that RhoA undergoes rapid degradation under basal conditions.
We then performed a series of experiments to study RhoA degradation induced by BDNF in hippocampal slices and cortical synaptoneurosomes. RhoA has previously been reported to be a calpain substrate in vitro (Kulkarni et al., 2002), and it is also degraded by the proteasome in response to long-term treatment with BDNF in hippocampal neurons (Cheng et al., 2011). Cortical synaptoneurosomes were treated with BDNF for various periods of time in the absence or presence of calpain inhibitor III 
A
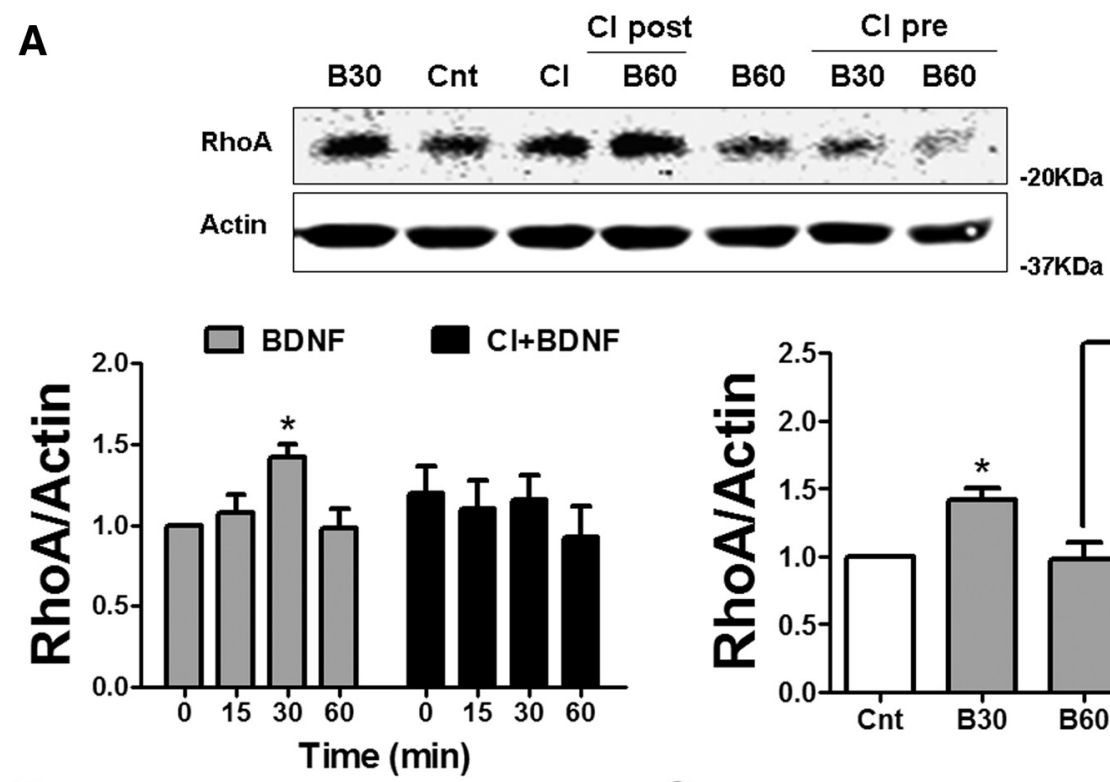

B
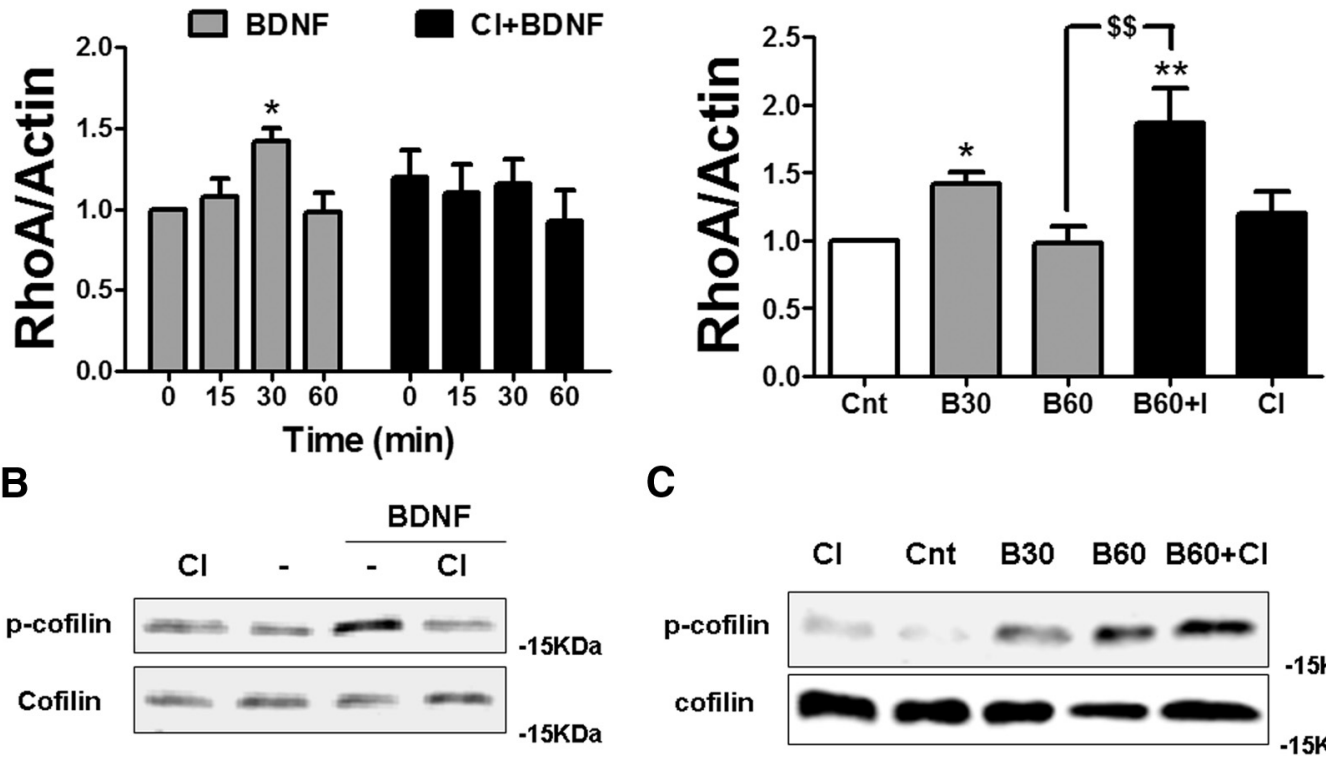

C
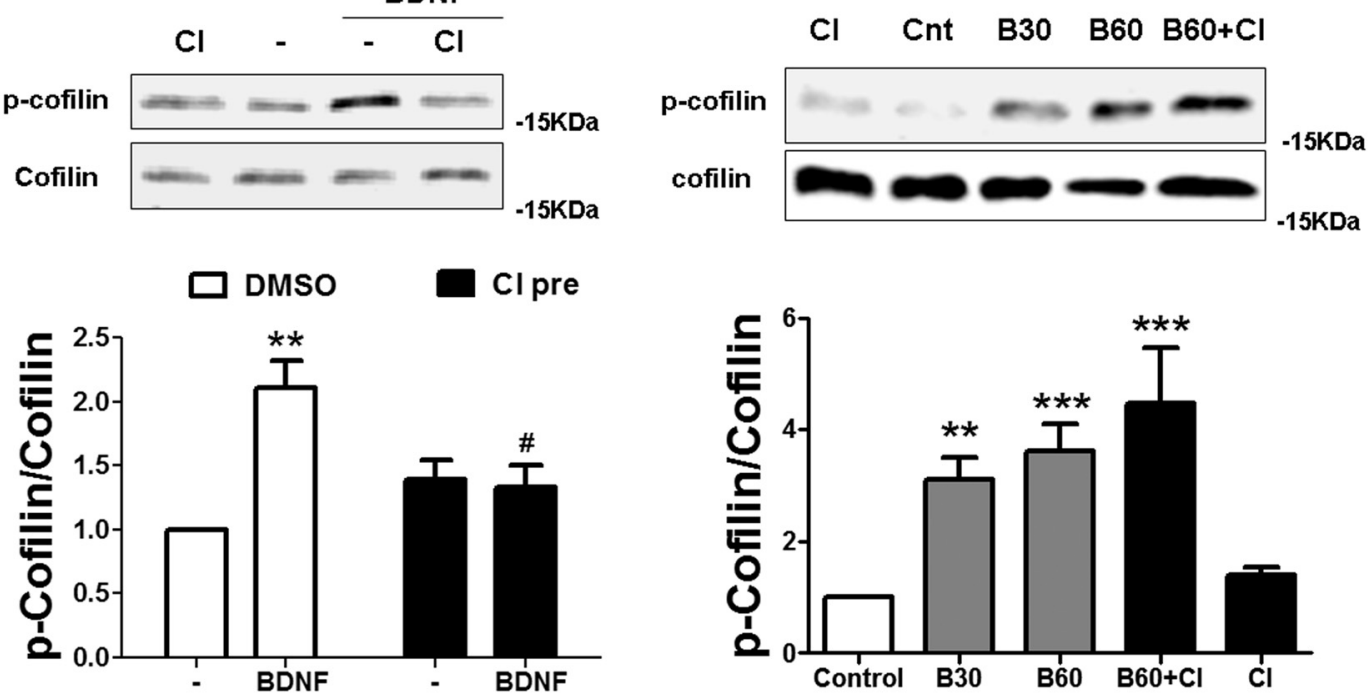

D

E
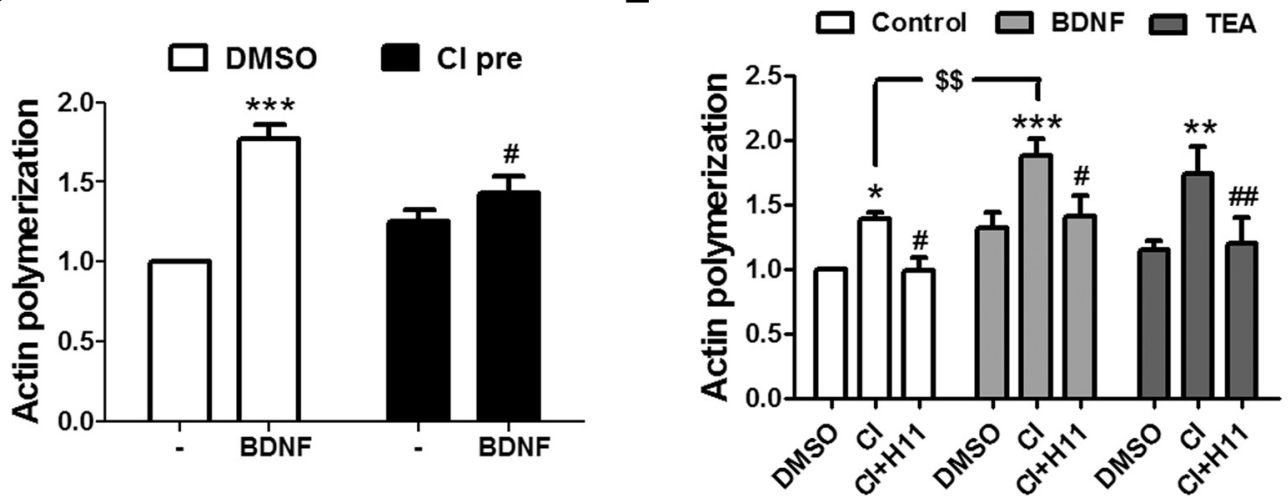

Figure 6. Effects of $\mathrm{Cl}$ on BDNF-induced changes in RhoA levels and actin polymerization. Cortical synaptoneurosomes ( $\boldsymbol{A}$ ) or hippocampal slices ( $\boldsymbol{B}-\boldsymbol{E}$ ) were pretreated with DMSO (control) or 10 $\mu \mathrm{MCl}(C \mathrm{pre})$ for $30 \mathrm{~min}$ and then incubated with BDNF for an additional $30 \mathrm{~min}(\boldsymbol{B}, \boldsymbol{D})$ or the indicated times $(\boldsymbol{A}$, bottom left); alternatively, slices were incubated with Cl $30 \mathrm{~min}$ after BDNF treatment (Cl post) or 15 min after TEA treatment in the absence or presence of $200 \mathrm{~nm} \mathrm{H1152} \mathrm{(H11)} \mathrm{and} \mathrm{maintained} \mathrm{for} \mathrm{an} \mathrm{additional} 30-45$ min, respectively $(A$, bottom right, $C, E)$. Data are presented as the ratio (fold of control) of the following: (A) RhoA over actin $(n=3-8),(\boldsymbol{B})$ p-cofilin over total cofilin $(n=3)$, (C) p-cofilin over total cofilin $(n=3-10)$. $\boldsymbol{D}, \boldsymbol{E}$, Data are presented as phalloidin fluorescence values normalized to control $(n=4-11) .{ }^{*} p<0.05$, ${ }^{* *} p<0.01,{ }^{* * *} p<0.001$ versus control or DMSO (E); ${ }^{\#} p<0.05,{ }^{\# \#} p<0.01$ versus BDNF alone or Cl (E); ${ }^{\$ \$} p<0.01$ (one or two-way ANOVA). 
A
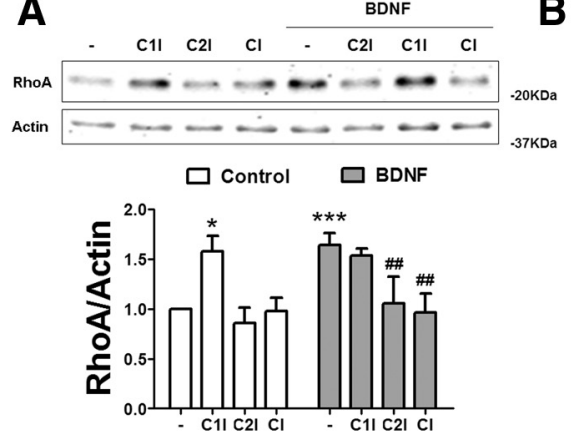

D
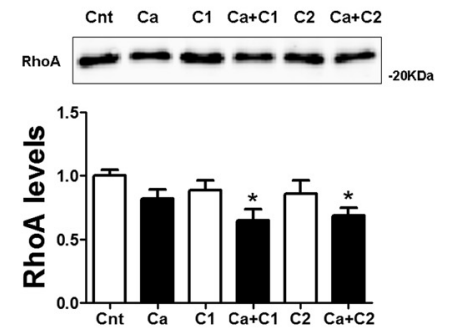

B
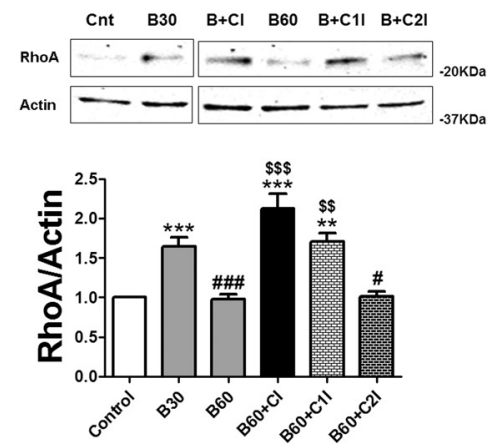

$\mathbf{E}$

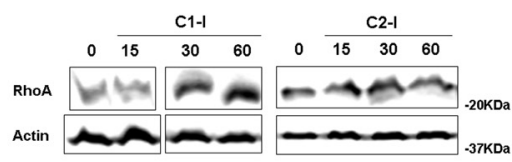

C
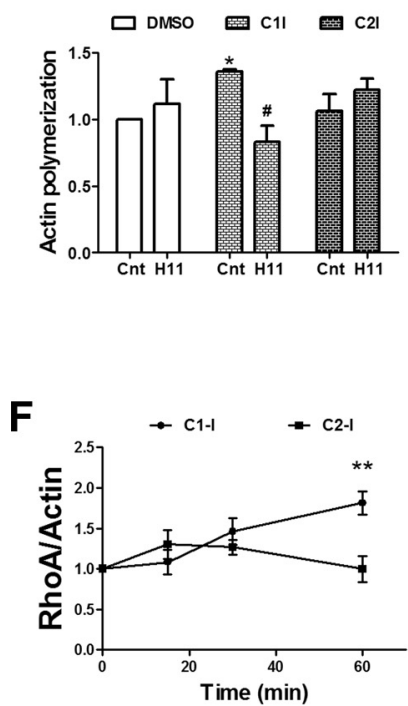

Figure 7. Effect of isoform-selective calpain inhibitors on RhoA levels and actin polymerization. C2I blocks RhoA synthesis (A) and C1I blocks RhoA degradation ( $\boldsymbol{B}$ ) induced by BDNF. Hippocampal slices were as follows: (A) pretreated with DMSO (-), $2 \mu \mathrm{M}$ C1I, $200 \mathrm{~nm} \mathrm{C2I,} \mathrm{or} 10 \mu \mathrm{M} C \mathrm{Cl}$ for $30 \mathrm{~min}$, and then incubated with BDNF for an additional 30 min; or (B) incubated with DMSO, C1I, C2I, or $\mathrm{Cl} 30 \mathrm{~min}$ after BDNF treatment for an additional $30 \mathrm{~min}$. Data are presented as the ratio (fold of control) of RhoA over actin $(n=3-13)$. C, C1l stimulates actin polymerization via RhoA/ROCK pathway. Slices were incubated with DMSO, C1I, or C2I in the absence or presence of $200 \mathrm{~nm} \mathrm{H1152} \mathrm{(H11).} \mathrm{Data} \mathrm{are} \mathrm{presented} \mathrm{as} \mathrm{phalloidin} \mathrm{fluorescence} \mathrm{values} \mathrm{normalized} \mathrm{to} \mathrm{control} \mathrm{(} n=3-7)$. $\boldsymbol{D}$, RhoA is cleaved in vitro by both calpain-1 and calpain-2. Brain homogenates were treated with purified calpain-1 (C1) or calpain-2 (C2) (both at $2.4 \mathrm{U} / \mathrm{ml})$ in the absence or presence of $2 \mathrm{~mm}$ calcium (Ca) for $30 \mathrm{~min}$ at $37^{\circ} \mathrm{C}$. After treatments, samples were homogenized and processed for Western blot $(n=4$ or 5$)$. Immunoblots $(\boldsymbol{E})$ and quantitative analysis $(\boldsymbol{F})$ for the time-dependent changes of RhoA levels induced by C1l and (2I in synaptoneurosomes. Data are presented as the ratio (fold of control) of RhoA over actin $(n=6)$. ${ }^{*} p<0.05,{ }^{* *} p<0.01,{ }^{* * *} p<0.001$ versus control; ${ }^{*} p<$ $0.05,{ }^{\# \#} p<0.01,{ }^{\# \# \#} p<0.001$ compared with $(\boldsymbol{A})$ BDNF alone, $(\boldsymbol{B}) \mathrm{B} 30$, or $(\boldsymbol{C})$ C1I; ${ }^{\$ \$} p<0.01,{ }^{\$ \$ \$} p<0.001$ compared with B60 (one- or tw0-way AN0VA).

(CI, $10 \mu \mathrm{M})$. Treatment with CI alone for $30 \mathrm{~min}$ did not significantly affect RhoA levels (Fig. $6 \mathrm{~A}$ ), but $30 \mathrm{~min}$ treatment with CI before BDNF blocked the increase in RhoA levels (Fig. 6A). In contrast, when CI was applied 30 min after BDNF treatment and the incubation continued for another $30 \mathrm{~min}$, RhoA levels remained elevated (Fig. 6A, right). Similar results were obtained in hippocampal slices (Fig. $7 A, B$ ). To test whether the ubiquitinproteosome pathway was involved in BDNF-induced RhoA degradation, we applied the proteosome inhibitor MG132 (25 $\mu \mathrm{M})$ 30 min after BDNF treatment. However, RhoA levels returned to basal levels in slices treated with BDNF in the presence of MG132 (data not shown), ruling out the involvement of the proteosome in activity-mediated RhoA degradation. Changes in RhoA levels under all these different conditions were associated with parallel modifications in cofilin phosphorylation and actin polymerization in slices. Thus, preapplication of CI blocked BDNF-induced cofilin phosphorylation and actin polymerization (Fig. $6 B, D$ ). In contrast, postapplication of CI further enhanced actin polymerization compared with BDNF or CI alone (Fig. 6E). Phosphocofilin levels were also higher when CI was added 30 min after BDNF, although the effect was not statistically significant compared with BDNF alone (Fig. $6 C$ ). These findings strongly suggest that there is a positive correlation between RhoA protein levels and actin cytoskeletal dynamics. To directly test this hypothesis, we incubated hippocampal slices with CI 30 min after BDNF in the presence of the ROCK inhibitor and $30 \mathrm{~min}$ later determined changes in actin polymerization. Under these conditions, H1152 completely reversed the increase in actin polymerization induced by CI (Fig. 6E). We also applied CI $15 \mathrm{~min}$ after induction of chemical LTP and found a similar enhancement of actin polymerization $45 \mathrm{~min}$ later (60 $\mathrm{min}$ after chemical LTP induction).
The effect was again abrogated when $\mathrm{H} 1152$ was applied along with CI (Fig. 6F).

The above results indicated that calpain is involved in both RhoA synthesis and degradation elicited by BDNF. In a recent study, we found that the two major calpain isoforms, calpain-1 and -2 , also produced opposite effects on the synthesis and degradation of another synaptic protein, namely, suprachiasmatic nucleus oscillatory protein (SCOP), as calpain-1 rapidly degraded SCOP, whereas calpain-2 activation resulted in mTORmediated stimulation of SCOP synthesis (Wang et al., 2014). To test the hypothesis that different calpain isoforms could also have opposite roles on RhoA metabolism, we used isoform-selective calpain inhibitors on BDNF-mediated stimulation of RhoA synthesis and degradation in hippocampal slices. The respective selectivity of these inhibitors for calpain-1 and -2 was previously reported under conditions similar to the ones used here (Wang et al., 2013, 2014). Pretreatment with a calpain-1-specific inhibitor, PD151746 (C1I, $2 \mu \mathrm{M}$ ), did not affect the increase in RhoA levels caused by BDNF. In contrast, preincubation with a calpain-2specific inhibitor (C2I, $0.2 \mu \mathrm{M}$ ) or with CI completely blocked BDNF-induced increase in RhoA levels (Fig. 7A). These data indicate that calpain-2 activation is involved in BDNF-mediated stimulation of RhoA translation, a result in good agreement with our previous findings showing its important role in the regulation of mTOR-dependent protein synthesis (Briz et al., 2013). Interestingly, application of C1I alone significantly increased RhoA levels to a similar extent as BDNF (Fig. 7A), suggesting that calpain-1 could be involved in basal RhoA degradation. To directly test this possibility, we treated hippocampal slices with calpain-1 or -2-specific inhibitors $30 \mathrm{~min}$ after BDNF application, as described above for CI post-treatment. Under these con- 


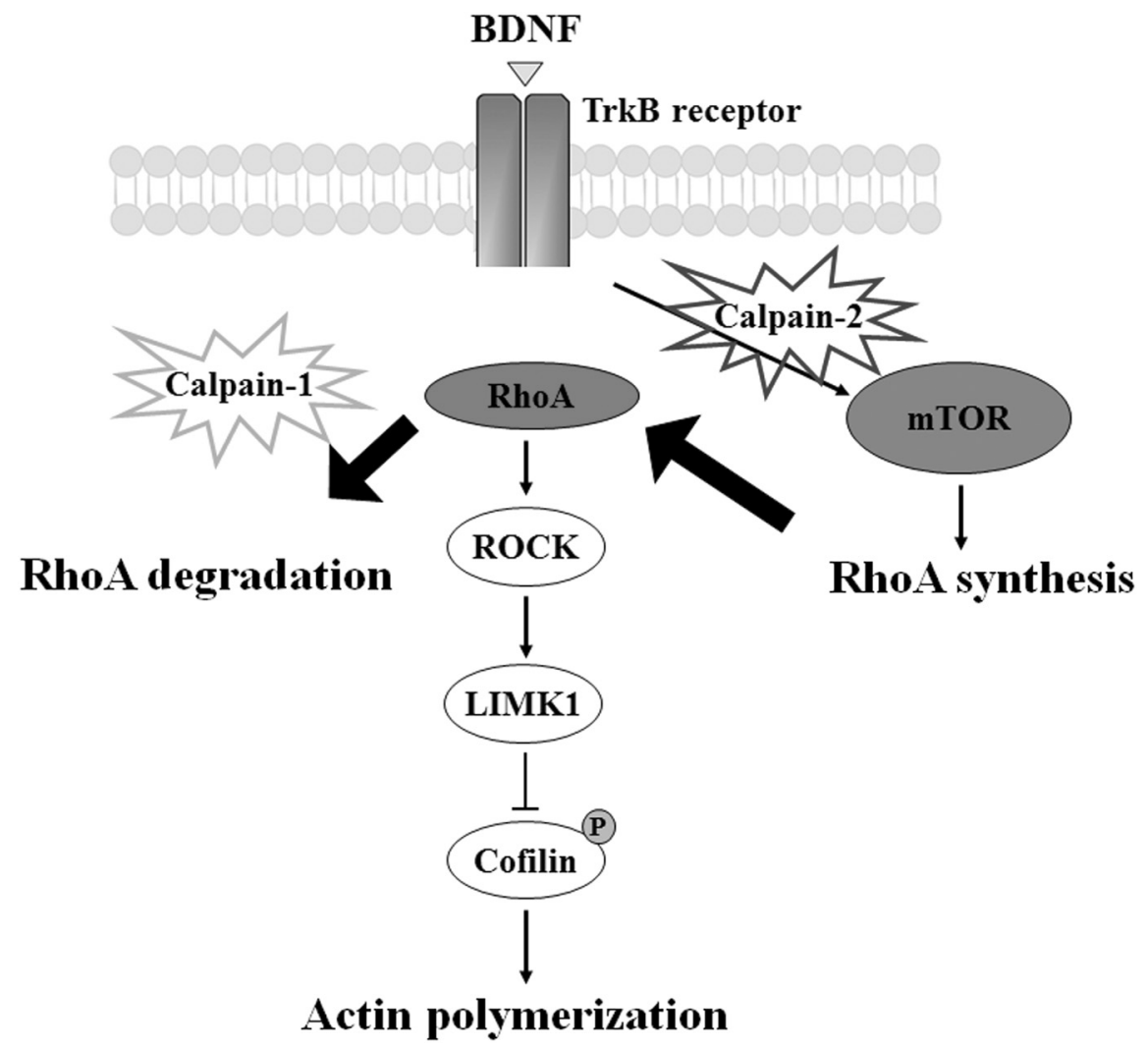

Figure 8. Regulation of RhoA levels and actin cytoskeleton reorganization by BDNF, mTOR, and calpain. Activation of TrkB receptor by BDNF rapidly stimulates RhoA synthesis through a mechanism involving calpain-2-mediated PTEN degradation and mTOR phosphorylation/activation. Newly translated RhoA proteins are then transported to the spine head, and upon activation, RhOA-GTP induces ROCK activation, which in turn phosphorylates and inhibits cofilin. This leads to polymerization of actin filaments and structural reorganization of dendritic spines, a necessary event for LTP consolidation. Finally, spine RhoA is rapidly eliminated by calpain-1-mediated degradation.

ditions, BDNF-induced RhoA degradation was blocked in the presence of C1I or CI but not of C2I (Fig. 7B). Similarly, C1I, but not C2I, produced a time-dependent increase in RhoA levels in synaptoneurosomes (Fig. 7E). These results confirm that calpain-1 mediates RhoA degradation either in stimulated cells or under resting conditions. In contrast, both calpain- 1 and- 2 were able to cleave RhoA in membrane fractions prepared from rat cerebrum (Fig. $7 D$ ), suggesting that an intact preparation is needed to preserve the isoform selectivity of BDNF-mediated stimulation of RhoA proteolysis. Because CI was found to affect basal levels of actin polymerization (Fig. $6 E$ ), we tested the effects of C1I and C2I on the reorganization of the actin cytoskeleton. Consistent with their effects on RhoA levels, a 30 min treatment with C1I, but not with C2I, increased actin polymerization, and this effect was blocked by the ROCK inhibitor, H1152 (Fig. 7E). Together, these results indicate that different calpain isoforms mediate RhoA synthesis and degradation.

\section{Discussion}

Dendritic RhoA synthesis is required for activity-dependent synaptic plasticity in hippocampus

Our results indicated that RhoA is rapidly translated in response to synaptic stimulation, and we provided direct evidence that this mechanism represents a critical step for LTP consolidation in the CA1 area of hippocampus. Although this issue remains controversial, dendritic protein synthesis appears to play a critical role in activity-dependent synaptic plasticity in the Schaffer-collateral pathway (Sutton and Schuman, 2006; Abraham and Williams,
2008; Panja and Bramham, 2014). In addition, several proteins have been shown to be locally synthesized during LTP consolidation (Håvik et al., 2003; Hernandez et al., 2003; Messaoudi et al., 2007) or in response to BDNF (Schratt et al., 2004). Despite this, there is still limited information regarding the specific proteins whose translation is necessary for LTP consolidation.

We used intrahippocampal injections of asODN directed against the translation initiation site of RhoA to specifically block de novo RhoA synthesis in dendrites without affecting basal levels of the protein. This approach has been previously used to successfully block synthesis of another protein involved in synaptic plasticity, namely, Arc (Guzowski et al., 2000; Messaoudi et al., 2007). In those studies, the authors showed that intrahippocampal injections of Arc asODN into the dentate gyrus rapidly reversed actin dynamics, LTP consolidation, and spatial memory. Another study reported impaired LTP and memory consolidation in knock-out mice lacking the dendritic targeting signal of CaMKII mRNA (Miller et al., 2002). In the present work, we identified another protein, RhoA, whose translation is critical for hippocampal synaptic plasticity. Interestingly, RhoA asODN increased paired-pulse facilitation compared with scrambled ODN, suggesting an additional role for RhoA synthesis in presynaptic plasticity. These data are consistent with the previously reported involvement of RhoA in neurotransmitter release (McMullan et al., 2006). Overall, both presynaptically and postsynaptically located RhoA contributes to its effects on LTP (Wang et al., 2005).

\section{Molecular mechanisms for activity-dependent cytoskeletal reorganization}

$\mathrm{BDNF}$ is a major mediator of cytoskeletal reorganization in dendritic spines during LTP (Rex et al., 2007). Our present results indicate that RhoA/ROCK activation (but not PAK) signaling is responsible for the effects of BDNF on actin polymerization in hippocampal slices, a result in good agreement with results supporting the involvement of this pathway in LTP consolidation (Rex et al., 2009). In contrast, both ROCK and PAK activation contributed to actin polymerization triggered during chemical LTP. Similarly, we recently reported that estradiol-mediated regulation of actin cytoskeletal dynamics involves activation of the same signaling pathways (Briz and Baudry, 2014). In that study, we proposed a model in which estradiol, by acting on classical estrogen receptors, activates RhoA/ROCK and PAK1/4, leading to cofilin phosphorylation and actin cytoskeleton reorganization, whereas estradiol stimulation of G-protein coupled receptor 30 triggers BDNF-mediated PAK2/3 phosphorylation and stabilization of the actin cytoskeleton. The present results using different concentrations of a PAK-specific inhibitor suggest that TEA may also differently modulate actin dynamics via PAK $1 / 4$ and PAK2/3 isoforms. This conclusion is based on the facts that: (1) TEAinduced actin polymerization was totally suppressed by the low- 
est concentration of the PAK inhibitor, which blocks PAK1/4 but not PAK2/3 (Murray et al., 2010); and (2) TEA-induced PAK phosphorylation was completely abolished only by the highest concentration of the PAK inhibitor, which suggests an additional contribution of PAK2/3 to the effect of TEA on PAK activation. Although previous work indicated that TBS-induced LTP consolidation did not require Rac/PAK signaling (Rex et al., 2009), we used a different PAK inhibitor (IPA-3), which does not interact with PAK4. Thus, the involvement of PAK4 as well as of Ccd242 signaling in cofilin phosphorylation and F-actin formation during LTP cannot be ruled out, considering their prominent role in neuronal development (Dan et al., 2001; Chen et al., 2006). It is also likely that TEA triggers additional signaling pathways compared with TBS, which could account for the observed differences between these two types of manipulations (Hanse and Gustafsson, 1994). In support of this idea, HFS-induced LTP is impaired in PAK1 knock-out mice (Asrar et al., 2009). In any event, our results support the idea that BDNF-mediated RhoA/ ROCK activation is critical for activity-dependent actin polymerization and LTP consolidation (Rex et al., 2007, 2009).

In addition to stimulating LIMK1/cofilin pathway, RhoA/ ROCK signaling also regulates actin reorganization via myosin light chain phosphorylation during LTP (Rex et al., 2010). Furthermore, BDNF has been recently reported to activate RhoA/ ROCK/myosin light chain pathway in endothelial cells (Anastasia et al., 2014). Therefore, we cannot rule out the contribution of this pathway to BDNF effects on actin polymerization. Furthermore, a recent study found that BDNF-mediated Racl activation coordinates protein translation and actin polymerization through the scaffold protein CYFIP1 (De Rubeis et al., 2013), providing another link between these two important processes.

$\mathrm{BDNF}$ is a major regulator of axonal guidance during neuronal development through inactivation of the RhoA/ROCK/cofilin pathway (Chen et al., 2006). It is worth noting that BDNF has opposite effects on RhoA signaling depending on the neurodevelopmental stage, as it is inhibitory in developing neurons and stimulatory in mature neurons, respectively. A possible explanation for such a phenomenon could be that different receptors (p75 vs TrkB) mediate the effects of BDNF on RhoA and actin cytoskeleton (Gehler et al., 2004; Rex et al., 2007). RhoA translation has previously been reported to mediate semaphorin $3 \mathrm{~A}$ induced growth cone collapse (Wu et al., 2005). However, it is unlikely that RhoA synthesis is involved in BDNF-mediated neurite outgrowth because increased synthesis would presumably result in increased RhoA activity and growth cone collapse. In contrast, the effects of BDNF on neuronal differentiation involve degradation of RhoA and of its activator, Rho guanine nucleotide exchanging factor (Cheng et al., 2011; Lin et al., 2011), or the direct activation of LIMK1 (Dong et al., 2012). Our results indicated that protein synthesis contributes to BDNF- or TBS-elicited stimulation of RhoA/ROCK/cofilin pathway and actin polymerization in adult hippocampal slices. Thus, different mechanisms link BDNF signaling to RhoA and actin cytoskeletal dynamics in developing and mature neurons.

\section{Novel role for calpain in the regulation of the actin cytoskeleton}

Calpain was involved in both the synthesis and degradation of RhoA, with calpain-2 activation stimulating RhoA synthesis, whereas calpain-1 activation-mediated RhoA degradation (Fig. 8 ). The opposite roles of calpain-1 and calpain-2 in BDNFmediated RhoA degradation and synthesis are similar to what we recently reported for BDNF-mediated changes in SCOP and are related to the recently identified function of calpain-2 in the regulation of BDNF-elicited mTOR-dependent dendritic protein synthesis through calpain-2-mediated PTEN degradation (Briz et al., 2013). Our results are also consistent with previous studies showing that RhoA is a calpain-1 substrate both in vivo and in vitro (Kulkarni et al., 2002; Kuchay et al., 2012). The fact that calpain-2 was also able to cleave RhoA in isolated brain membranes (but not in slices or synaptoneurosomes) suggests that the in situ selectivity of calpain-1 toward RhoA might be related to a specific subcellular localization and/or association of calpain-1 with specific protein scaffold complexes. In support of this notion, we recently reported that calpain- 1 and -2 are specifically activated by synaptic and extrasynaptic NMDA receptors, respectively, to oppositely regulate neuronal fate (Wang et al., 2013). In Figure 8, we propose a model in which BDNF stimulation triggers rapid dendritic translation of RhoA through calpain-2-mediated PTEN truncation and the resulting stimulation of mTORdependent protein synthesis. Newly synthesized RhoA proteins would be transported to dendritic spines, where they would stimulate reorganization of the actin cytoskeleton through ROCKmediated cofilin phosphorylation, and inactivation. In parallel, spine RhoA would be degraded by calpain-1.

Emerging evidence indicates that calpains are key regulators of synaptic plasticity as well as neurodegeneration ( $\mathrm{Wu}$ and Lynch, 2006; Zadran et al., 2010). Calpain-mediated spectrin truncation has been implicated in reorganization of the actin cytoskeleton during LTP (Lynch and Baudry, 1984; Lynch et al., 2007). Our results further demonstrate a novel role for calpains in regulating structural synaptic plasticity by controlling RhoA protein availability. Treatment with the specific calpain-1 inhibitor rapidly enhanced RhoA levels and stimulated actin polymerization in a ROCK-sensitive manner, indicating that RhoA upregulation is sufficient to stimulate actin cytoskeletal dynamics. Interestingly, calpain-1 knock-out mice exhibit increased levels of RhoA and enhanced platelet spreading (Kuchay et al., 2012). Therefore, it is tempting to speculate that hippocampal neurons from these mice might have higher levels of spine F-actin and increase spine size, given the role of RhoA/ROCK signaling in spine growth (Schubert et al., 2006; Murakoshi et al., 2011). However, this might not be the case, as opposite effects on dendritic spine morphology were found following overexpression of constitutively active RhoA (Nakayama et al., 2000).

In conclusion, the present study shed new light into the mechanisms regulating activity-dependent synaptic plasticity in hippocampus. RhoA is rapidly and locally synthesized and degraded in response to synaptic stimulation, resulting in reorganization of actin cytoskeleton in dendritic spines during LTP. This mechanism provides a novel link between dendritic protein synthesis and actin polymerization, two major events required for hippocampal LTP and memory consolidation.

\section{References}

Abraham WC, Williams JM (2008) LTP maintenance and its protein synthesis-dependence. Neurobiol Learn Mem 89:260-268. CrossRef Medline

Alarcon JM, Hodgman R, Theis M, Huang YS, Kandel ER, Richter JD (2004) Selective modulation of some forms of schaffer collateral-CA1 synaptic plasticity in mice with a disruption of the CPEB-1 gene. Learn Mem 11:318-327. CrossRef Medline

Anastasia A, Deinhardt K, Wang S, Martin L, Nichol D, Irmady K, Trinh J, Parada L, Rafii S, Hempstead BL, Kermani P (2014) Trkb signaling in pericytes is required for cardiac microvessel stabilization. PLoS One 9:e87406. CrossRef Medline

Asrar S, Meng Y, Zhou Z, Todorovski Z, Huang WW, Jia Z (2009) Regula- 
tion of hippocampal long-term potentiation by $\mathrm{p} 21$-activated protein kinase 1 (PAK1). Neuropharmacology 56:73-80. CrossRef Medline

Bolte S, Cordelières FP (2006) A guided tour into subcellular colocalization analysis in light microscopy. J Microsc 224:213-232. CrossRef Medline

Briz V, Baudry M (2014) Estrogen regulates protein synthesis and actin polymerization in hippocampal neurons through different molecular mechanisms. Front Endocrinol (Lausanne) 5:22. CrossRef Medline

Briz V, Hsu YT, Li Y, Lee E, Bi X, Baudry M (2013) Calpain-2-mediated PTEN degradation contributes to BDNF-induced stimulation of dendritic protein synthesis. J Neurosci 33:4317-4328. CrossRef Medline

Cajigas IJ, Tushev G, Will TJ, tom Dieck S, Fuerst N, Schuman EM (2012) The local transcriptome in the synaptic neuropil revealed by deep sequencing and high-resolution imaging. Neuron 74:453-466. CrossRef Medline

Chen LY, Rex CS, Casale MS, Gall CM, Lynch G (2007) Changes in synaptic morphology accompany actin signaling during LTP. J Neurosci 27:53635372. CrossRef Medline

Chen TJ, Gehler S, Shaw AE, Bamburg JR, Letourneau PC (2006) Cdc42 participates in the regulation of $\mathrm{ADF} /$ cofilin and retinal growth cone filopodia by brain derived neurotrophic factor. J Neurobiol 66:103-114. CrossRef Medline

Cheng PL, Lu H, Shelly M, Gao H, Poo MM (2011) Phosphorylation of E3 ligase Smurf1 switches its substrate preference in support of axon development. Neuron 69:231-243. CrossRef Medline

Chotiner JK, Nielson J, Farris S, Lewandowski G, Huang F, Banos K, de Leon R, Steward O (2010) Assessment of the role of MAP kinase in mediating activity-dependent transcriptional activation of the immediate early gene Arc/Arg3.1 in the dentate gyrus in vivo. Learn Mem 17:117-129. CrossRef Medline

Dan C, Kelly A, Bernard O, Minden A (2001) Cytoskeletal changes regulated by the PAK4 serine/threonine kinase are mediated by LIM kinase 1 and cofilin. J Biol Chem 276:32115-32121. CrossRef Medline

De Rubeis S, Pasciuto E, Li KW, Fernández E, Di Marino D, Buzzi A, Ostroff LE, Klann E, Zwartkruis FJ, Komiyama NH, Grant SG, Poujol C, Choquet D, Achsel T, Posthuma D, Smit AB, Bagni C (2013) CYFIP1 coordinates mRNA translation and cytoskeleton remodeling to ensure proper dendritic spine formation. Neuron 79:1169-1182. CrossRef Medline

Dong Q, Ji YS, Cai C, Chen ZY (2012) LIM kinase 1 (LIMK1) interacts with tropomyosin-related kinase $\mathrm{B}(\mathrm{TrkB})$ and mediates brain-derived neurotrophic factor (BDNF)-induced axonal elongation. J Biol Chem 287: 41720-41731. CrossRef Medline

Edwards DC, Sanders LC, Bokoch GM, Gill GN (1999) Activation of LIMkinase by Pak1 couples Rac/Cdc42 GTPase signalling to actin cytoskeletal dynamics. Nat Cell Biol 1:253-259. CrossRef Medline

Fukazawa Y, Saitoh Y, Ozawa F, Ohta Y, Mizuno K, Inokuchi K (2003) Hippocampal LTP is accompanied by enhanced F-actin content within the dendritic spine that is essential for late LTP maintenance in vivo. Neuron 38:447-460. CrossRef Medline

Garcia-Osta A, Tsokas P, Pollonini G, Landau EM, Blitzer R, Alberini CM (2006) MuSK expressed in the brain mediates cholinergic responses, synaptic plasticity, and memory formation. J Neurosci 26:7919-7932. CrossRef Medline

Gehler S, Gallo G, Veien E, Letourneau PC (2004) p75 neurotrophin receptor signaling regulates growth cone filopodial dynamics through modulating RhoA activity. J Neurosci 24:4363-4372. CrossRef Medline

Guo D, Sun W, Zhu L, Zhang H, Hou X, Liang J, Jiang X, Liu C (2012) Knockdown of BDNF suppressed invasion of HepG2 and HCCLM3 cells, a mechanism associated with inactivation of RhoA or Racl and actin skeleton disorganization. APMIS 120:469-476. CrossRef Medline

Guzowski JF, Lyford GL, Stevenson GD, Houston FP, McGaugh JL, Worley PF, Barnes CA (2000) Inhibition of activity-dependent arc protein expression in the rat hippocampus impairs the maintenance of long-term potentiation and the consolidation of long-term memory. J Neurosci 20:3993-4001. Medline

Hanse E, Gustafsson B (1994) TEA elicits two distinct potentiations of synaptic transmission in the CA1 region of the hippocampal slice. J Neurosci 14:5028-5034. Medline

Håvik B, Røkke H, Bårdsen K, Davanger S, Bramham CR (2003) Bursts of high-frequency stimulation trigger rapid delivery of preexisting alphaCaMKII mRNA to synapses: a mechanism in dendritic protein synthesis during long-term potentiation in adult awake rats. Eur J Neurosci 17: 2679-2689. CrossRef Medline
Hernandez AI, Blace N, Crary JF, Serrano PA, Leitges M, Libien JM, Weinstein G, Tcherapanov A, Sacktor TC (2003) Protein kinase M zeta synthesis from a brain mRNA encoding an independent protein kinase $\mathrm{C}$ zeta catalytic domain: implications for the molecular mechanism of memory. J Biol Chem 278:40305-40316. CrossRef Medline

Huang YY, Kandel ER (2005) Theta frequency stimulation induces a local form of late phase LTP in the CA1 region of the hippocampus. Learn Mem 12:587-593. CrossRef Medline

Jourdi H, Hsu YT, Zhou M, Qin Q, Bi X, Baudry M (2009) Positive AMPA receptor modulation rapidly stimulates $\mathrm{BDNF}$ release and increases dendritic mRNA translation. J Neurosci 29:8688-8697. CrossRef Medline

Kramár EA, Lin B, Rex CS, Gall CM, Lynch G (2006) Integrin-driven actin polymerization consolidates long-term potentiation. Proc Natl Acad Sci U S A 103:5579-5584. CrossRef Medline

Kuchay SM, Wieschhaus AJ, Marinkovic M, Herman IM, Chishti AH (2012) Targeted gene inactivation reveals a functional role of calpain-1 in platelet spreading. J Thromb Haemost 10:1120-1132. CrossRef Medline

Kulkarni S, Goll DE, Fox JE (2002) Calpain cleaves RhoA generating a dominant-negative form that inhibits integrin-induced actin filament assembly and cell spreading. J Biol Chem 277:24435-24441. CrossRef Medline

Lin MY, Lin YM, Kao TC, Chuang HH, Chen RH (2011) PDZ-RhoGEF ubiquitination by Cullin3-KLHL20 controls neurotrophin-induced neurite outgrowth. J Cell Biol 193:985-994. CrossRef Medline

Lynch G, Baudry M (1984) The biochemistry of memory: a new and specific hypothesis. Science 224:1057-1063. CrossRef Medline

Lynch G, Rex CS, Gall CM (2007) LTP consolidation: substrates, explanatory power, and functional significance. Neuropharmacology 52:12-23. CrossRef Medline

Maekawa M, Ishizaki T, Boku S, Watanabe N, Fujita A, Iwamatsu A, Obinata T, Ohashi K, Mizuno K, Narumiya S (1999) Signaling from Rho to the actin cytoskeleton through protein kinases ROCK and LIM-kinase. Science 285:895-898. CrossRef Medline

McMullan R, Hiley E, Morrison P, Nurrish SJ (2006) Rho is a presynaptic activator of neurotransmitter release at pre-existing synapses in C. elegans. Genes Dev 20:65-76. CrossRef Medline

Messaoudi E, Kanhema T, Soulé J, Tiron A, Dagyte G, da Silva B, Bramham CR (2007) Sustained Arc/Arg3.1 synthesis controls long-term potentiation consolidation through regulation of local actin polymerization in the dentate gyrus in vivo. J Neurosci 27:10445-10455. CrossRef Medline

Miller S, Yasuda M, Coats JK, Jones Y, Martone ME, Mayford M (2002) Disruption of dendritic translation of CaMKIIalpha impairs stabilization of synaptic plasticity and memory consolidation. Neuron 36:507-519. CrossRef Medline

Murakoshi H, Wang H, Yasuda R (2011) Local, persistent activation of Rho GTPases during plasticity of single dendritic spines. Nature 472:100-104. CrossRef Medline

Murray BW, Guo C, Piraino J, Westwick JK, Zhang C, Lamerdin J, Dagostino E, Knighton D, Loi CM, Zager M, Kraynov E, Popoff I, Christensen JG, Martinez R, Kephart SE, Marakovits J, Karlicek S, Bergqvist S, Smeal T (2010) Small-molecule p21-activated kinase inhibitor PF-3758309 is a potent inhibitor of oncogenic signaling and tumor growth. Proc Natl Acad Sci U S A 107:9446-9451. CrossRef Medline

Nakayama AY, Harms MB, Luo L (2000) Small GTPases Rac and Rho in the maintenance of dendritic spines and branches in hippocampal pyramidal neurons. J Neurosci 20:5329-5338. Medline

Olenik C, Barth H, Just I, Aktories K, Meyer DK (1997) Gene expression of the small GTP-binding proteins RhoA, RhoB, Racl, and Cdc42 in adult rat brain. Brain Res Mol Brain Res 52:263-269. CrossRef Medline

Panja D, Bramham CR (2014) BDNF mechanisms in late LTP formation: a synthesis and breakdown. Neuropharmacology 76:664-676. CrossRef Medline

Panja D, Dagyte G, Bidinosti M, Wibrand K, Kristiansen AM, Sonenberg N, Bramham CR (2009) Novel translational control in Arc-dependent long term potentiation consolidation in vivo. J Biol Chem 284:31498-31511. CrossRef Medline

Penzes P, Rafalovich I (2012) Regulation of the actin cytoskeleton in dendritic spines. Adv Exp Med Biol 970:81-95. CrossRef Medline

Qin Q, Liao G, Baudry M, Bi X (2010) Cholesterol perturbation in mice results in p53 degradation and axonal pathology through p38 MAPK and Mdm2 activation. PLoS One 5:e9999. CrossRef Medline

Rex CS, Lin CY, Kramár EA, Chen LY, Gall CM, Lynch G (2007) Brain- 
derived neurotrophic factor promotes long-term potentiation-related cytoskeletal changes in adult hippocampus. J Neurosci 27:3017-3029. CrossRef Medline

Rex CS, Chen LY, Sharma A, Liu J, Babayan AH, Gall CM, Lynch G (2009) Different Rho GTPase-dependent signaling pathways initiate sequential steps in the consolidation of long-term potentiation. J Cell Biol 186:85-97. CrossRef Medline

Rex CS, Gavin CF, Rubio MD, Kramar EA, Chen LY, Jia Y, Huganir RL, Muzyczka N, Gall CM, Miller CA, Lynch G, Rumbaugh G (2010) Myosin IIb regulates actin dynamics during synaptic plasticity and memory formation. Neuron 67:603-617. CrossRef Medline

Schratt GM, Nigh EA, Chen WG, Hu L, Greenberg ME (2004) BDNF regulates the translation of a select group of mRNAs by a mammalian target of rapamycin-phosphatidylinositol 3-kinase-dependent pathway during neuronal development. J Neurosci 24:7366-7377. CrossRef Medline

Schratt GM, Tuebing F, Nigh EA, Kane CG, Sabatini ME, Kiebler M, Greenberg ME (2006) A brain-specific microRNA regulates dendritic spine development. Nature 439:283-289. CrossRef Medline

Schubert V, Da Silva JS, Dotti CG (2006) Localized recruitment and activation of RhoA underlies dendritic spine morphology in a glutamate receptor-dependent manner. J Cell Biol 172:453-467. CrossRef Medline

Sutton MA, Schuman EM (2006) Dendritic protein synthesis, synaptic plasticity, and memory. Cell 127:49-58. CrossRef Medline

Torsoni AS, Marin TM, Velloso LA, Franchini KG (2005) RhoA/ROCK signaling is critical to FAK activation by cyclic stretch in cardiac myocytes. Am J Physiol Heart Circ Physiol 289:H1488-H1496. CrossRef Medline

Troca-Marín JA, Alves-Sampaio A, Tejedor FJ, Montesinos ML (2010) Lo- cal translation of dendritic RhoA revealed by an improved synaptoneurosome preparation. Mol Cell Neurosci 43:308-314. CrossRef Medline

Wang HG, Lu FM, Jin I, Udo H, Kandel ER, de Vente J, Walter U, Lohmann SM, Hawkins RD, Antonova I (2005) Presynaptic and postsynaptic roles of NO, cGK, and RhoA in long-lasting potentiation and aggregation of synaptic proteins. Neuron 45:389-403. CrossRef Medline

Wang Y, Briz V, Chishti A, Bi X, Baudry M (2013) Distinct roles for mucalpain and m-calpain in synaptic NMDAR-mediated neuroprotection and extrasynaptic NMDAR-mediated neurodegeneration. J Neurosci 33: 18880-18892. CrossRef Medline

Wang Y, Zhu G, Briz V, Hsu YT, Bi X, Baudry M (2014) A molecular brake controls the magnitude of long-term potentiation. Nat Commun 5:3051. CrossRef Medline

Wu HY, Lynch DR (2006) Calpain and synaptic function. Mol Neurobiol 33:215-236. CrossRef Medline

Wu KY, Hengst U, Cox LJ, Macosko EZ, Jeromin A, Urquhart ER, Jaffrey SR (2005) Local translation of RhoA regulates growth cone collapse. Nature 436:1020-1024. CrossRef Medline

Yamauchi J, Chan JR, Shooter EM (2004) Neurotrophins regulate Schwann cell migration by activating divergent signaling pathways dependent on Rho GTPases. Proc Natl Acad Sci U S A 101:8774-8779. CrossRef Medline

Yuan XB, Jin M, Xu X, Song YQ, Wu CP, Poo MM, Duan S (2003) Signalling and crosstalk of Rho GTPases in mediating axon guidance. Nat Cell Biol 5:38-45. CrossRef Medline

Zadran S, Bi X, Baudry M (2010) Regulation of calpain-2 in neurons: implications for synaptic plasticity. Mol Neurobiol 42:143-150. CrossRef Medline 